\title{
Essential Oil-Loaded NLC for Potential Intranasal Administration
}

\author{
Angela Bonaccorso ${ }^{1,+} \mathbb{D}$, Cinzia Cimino ${ }^{1,+} \mathbb{D}$, Daniela Erminia Manno ${ }^{2} \mathbb{D}$, Barbara Tomasello ${ }^{1}$, Antonio Serra ${ }^{2} \mathbb{D}$, \\ Teresa Musumeci $^{1}$ (D), Giovanni Puglisi ${ }^{1}$, Rosario Pignatello ${ }^{1} \mathbb{D}$ and Claudia Carbone ${ }^{1, * \mathbb{D}}$
}

1 Laboratory of Drug Delivery Technology, Department of Drug and Health Sciences, University of Catania, Viale A. Doria 6, 95124 Catania, Italy; angela.bonaccorso@unict.it (A.B.); cinzia.cimino@phd.unict.it (C.C.); barbara.tomasello@unict.it (B.T.); teresa.musumeci@unict.it (T.M.); puglisig@unict.it (G.P.); rosario.pignatello@unict.it (R.P.)

2 Dipartimento di Matematica e Fisica, University of Salento, 73100 Lecce, Italy; daniela.manno@unisalento.it (D.E.M.); antonio.serra@unisalento.it (A.S.)

* Correspondence: claudia.carbone@unict.it; Tel.: +39-095-7384251

+ These authors contributed equally to this work.

Citation: Bonaccorso, A.; Cimino, C. Manno, D.E.; Tomasello, B.; Serra, A.; Musumeci, T.; Puglisi, G.; Pignatello, R.; Carbone, C. Essential Oil-Loaded NLC for Potential Intranasal

Administration. Pharmaceutics 2021, 13, 1166. https://doi.org/10.3390/ pharmaceutics13081166

Academic Editors: Anna Rita Bilia, Nadia Passerini, Paolo Caliceti,

Chiara Sinico and

Piroska Szabó-Révész

Received: 31 May 2021

Accepted: 27 July 2021

Published: 28 July 2021

Publisher's Note: MDPI stays neutral with regard to jurisdictional claims in published maps and institutional affiliations.

Copyright: (c) 2021 by the authors. Licensee MDPI, Basel, Switzerland. This article is an open access article distributed under the terms and conditions of the Creative Commons Attribution (CC BY) license (https:/ / creativecommons.org/licenses/by/ $4.0 /)$.

\begin{abstract}
Complementary and alternative medicines represent an interesting field of research on which worldwide academics are focusing many efforts. In particular, the possibility to exploit pharmaceutical technology strategies, such as the nanoencapsulation, for the delivery of essential oils is emerging as a promising strategy not only in Italy but also all over the world. The aim of this work was the development of nanostructured lipid carriers (NLC) for the delivery of essential oils (Lavandula, Mentha, and Rosmarinus) by intranasal administration, an interesting topic in which Italian contributions have recently increased. Essential oil-loaded NLC, projected as a possible add-on strategy in the treatment of neurodegenerative diseases, were characterized in comparison to control formulations prepared with Tegosoft CT and Neem oil. Homogeneous (polydispersity index, PDI < 0.2) nanoparticles with a small size $(<200 \mathrm{~nm})$ and good stability were obtained. Morphological and physical-chemical studies showed the formation of different structures depending on the nature of the liquid oil component. In particular, NLC prepared with Lavandula or Rosmarinus showed the formation of a more ordered structure with higher cytocompatibility on two cell lines, murine and human fibroblasts. Taken together, our preliminary results show that optimized positively charged NLC containing Lavandula or Rosmarinus can be proposed as a potential add-on strategy in the treatment of neurodegenerative diseases through intranasal administration, due to the well-known beneficial effects of essential oils and the mucoadhesive properties of NLC.
\end{abstract}

Keywords: nanomedicine; nose-to-brain; Lavandula; Mentha; Rosmarinus; TEM; cell viability; mucoadhesion

\section{Introduction}

Essential oils (EOs) are important natural mixtures produced by aromatic plants during their secondary metabolism, characterized by the presence of monoterpenes and sesquiterpenes, with other important aliphatic compounds, including terpenoids, alcohols, ethers, esters, ketones, and aldehydes [1]. Their quali-quantitative composition is influenced by several factors, including the variety of the plant, growing place (in particular, environment, climate, and eventual stress suffered), nutrition and fertilizers used, and extraction method. Due to the many properties of pharmaceutical interest (antioxidant, anti-inflammatory, antimicrobial, wound-healing, and anxiolytic), an increasing interest in complementary and alternative medicines (CAMs) has spread during the last years, with several studies exploring the potential use of EOs as adjuvants in various diseases, in particular when encapsulated into vesicular or nanoparticulate delivery systems [1-16]. The advantages of EOs encapsulation are related to the possibility to overcome different drawbacks by enhancing their stability, providing a controlled release and thus increasing their bioavailability and effectiveness. 
As recently described by Scuteri et al. [12], the use of EOs via inhalation (aromatherapy), such as Lavandula officinalis and Melissa officinalis, represents a complementary approach in the treatment of Alzheimer's disease (AD), since the treatment with antipsychotic drugs is limited by the short-term use (maximum 12 weeks). Even if the mechanisms of actions of EOs are still not clear, their ability to bind to the olfactory nerve system is responsible for the transmission of the signal to specific areas of the central nervous systems (hippocampus, limbic system, amygdala, and hypothalamus). The potential application of different EOs in AD treatment was also reported by Jimbo et al. [17], who developed a clinical trial on 28 elderly people affected by dementia, demonstrating the importance of aromatherapy in $\mathrm{AD}$ treatment. The success of the treatment, demonstrated by the resulting significant improvement in cognitive function, was based on the use of a combined therapy, with two administrations per day for 28 days, of four different EOs. In the morning, $0.04 \mathrm{~mL}$ of Citrus limon (L.) and $0.08 \mathrm{~mL}$ of Rosmarinus officinalis were administered based on the idea that this mixture is able to activate the sympathetic nervous system, thus promoting concentration and memory. In the evening, aiming to induce relaxation through the activation of the parasympathetic nervous system, a mixture constituted of $0.04 \mathrm{~mL}$ of Citrus sinensis (L.) Osbeck and $0.04 \mathrm{~mL}$ Lavandula angustifolia was administered. Interestingly, Rinaldi et al. recently developed chitosan coated nanoemulsions for the intranasal delivery of Thymus vulgaris and Syzygium aromaticum EOs, in the treatment of brain infections (meningitis and encephalitis) caused by bacterial strains of clinical concern [18]. The good mucoadhesive properties of nanoemulsions would enhance EOs' nasal administration, thus allowing EOs' antibacterial activity, as demonstrated on different bacterial strains [18].

Based on these considerations, the aim of this work was the development of EO-loaded nanostructured lipid carriers (NLC) for intranasal administration as potential adjuvant in the treatment of neurodegenerative diseases. Polymeric and lipid nanoparticles, solid lipid nanoparticles (SLN), and second-generation NLC have been widely investigated for brain targeting [18-31]. Herein, NLC were selected for their ability to directly release active compounds to the brain endothelial cells, as recently demonstrated by Arduino et al. [32]. Rosmarinus officinalis L., Lavandula $\times$ intermedia "Sumian", and Mentha piperita were selected due to their potential beneficial effects reported in AD treatment. Lavandula [33] and Rosmarinus [34] showed promising results in behavioral tests, demonstrating their ability to provide benefits in the treatment of scopolamine-induced Alzheimer's-type dementia. Lavandula was able to reduce depression, anxiety, and memory impairment [33], while Rosmarinus increased imaged and number memory in a trial carried out on school students [35]. Mentha EO was also found to enhance memorization process, through its ability to inhibit both acetylcholinesterase (AChE) and butyrylcholinesterase (BuChE) in a dosedependent manner, thus suggesting a potential use in the treatment of neurodegenerative disorders [36].

EO-loaded NLC were characterized from a physical-chemical and technological point of view in comparison to NLC prepared with Tegosoft CT oil, used as EO-free control formulation, and NLC loaded with Neem oil, used as negative control due to its documented toxic effects [37-39]. All NLC formulations were analyzed to determine their mean size, polydispersity, and zeta potential by photon correlation spectroscopy (PCS) analysis. NLC were also characterized in terms of osmolarity, $\mathrm{pH}$ measurements, entrapment efficiency $(\mathrm{EE} \%)$ of the loaded EO, and stability over time exploiting Turbiscan ${ }^{\circledR}$ AG Station. In order to highlight the potential influence of the liquid oil component on NLC structure and morphology, X-ray analysis, Raman spectrometry and transmission electron microscopy (TEM) were also performed. In vitro NLC cytocompatibility was assessed on two fibroblast cell lines, one murine (NIH-3T3) and one human (HFF1). Finally, mucoadhesive properties were evaluated on the selected NLC, optimized by the addition of a coating layer of the positively charged cationic lipid didodecyldimethylammonium bromide (DDAB). 


\section{Materials and Methods}

\subsection{Materials}

Kolliphor RH40 was provided by BASF Italia S.p.a. (Cesano Modena, Italy). Oleoyl Macrogol-6 Glycerides (Labrafil) was gifted by Gattefossé Italia s.r.l. (Milano, Italy). Hydrogenated Coco-Glycerides (Softisan 100) was bought from IOI Oleo GmbH (Oleochemicals, IOI group). Rosmarinus officinalis L. and Lavandula $\times$ intermedia "Sumian" essential oils were provided by Exentiae s.r.l. (Catania, Italy). Mentha piperita was gifted by the Department of Agriculture, Food and Environment (Di3A), University of Catania. Triglyceride capryliccapric (Tegosoft CT, Miglyol 812) was supplied by Farmalabor (Canosa di Puglia, Italy). Neem oil was supplied by La Saponaria (Vallefoglia, Italy). Dioctadecylammonium bromide (DDAB), mucin from porcine stomach type II, sodium chloride, potassium chloride, calcium chloride dehydrated, and polysorbate 80 were bought from Sigma (Milan, Italy).

\subsection{Nanoparticles Preparation}

NLC were produced by the phase inversion temperature (PIT) method, as previously described [40]. The lipid phase containing the surfactant mixture $(6.0 \% w / v$ of Kolliphor RH40 and $7.5 \% w / v$ of Labrafil) and the lipid Softisan $(10 \% w / v)$ and the aqueous phase were separately heated to $70{ }^{\circ} \mathrm{C}$. Then, the EO was added to the lipid phase at 1:1 ratio with the solid lipid. Finally, the aqueous phase was added dropwise to the lipid phase and the mixture was rapidly cooled in an ice bath under stirring for $1 \mathrm{~h}$, thus obtaining different NLC formulations: L-NLC, containing Lavandula; M-NLC, prepared with Mentha; R-NLC, using Rosmarinus. Tegosoft CT-loaded NLC (CT-NLC) were prepared as positive control, while Neem oil was used to obtain N-NLC, as negative control. The produced NLC were purified through ultracentrifuge (SL16R Centrifuge, Thermo Scientific, Rodano, Italy) at $13,000 \mathrm{rpm}$ for $2 \mathrm{~h}$ at $1^{\circ} \mathrm{C}$, in order to remove the excess surfactants from the colloidal suspensions. The obtained pellet was vortexed (Heidolph Reax 2000, VWR, Milan, Italy) for $60 \mathrm{~s}$.

\subsection{Photon Correlation Spectroscopy (PCS)}

After $24 \mathrm{~h}$ from the preparation, samples were diluted 1:10 in deionized water and analyzed using a Zetasizer Nano S90 (Malvern Instruments, Malvern, UK), in order to measure the mean particle size (Zave), the polydispersity index (PDI), and the zeta potential (ZP). The obtained values were reported as the mean of at least three measurements \pm standard deviation (SD).

\subsection{Osmolarity and $\mathrm{pH}$ Measurement}

The osmolarity of each formulation was detected using an osmometer (Osmomat 3000, Gonotec, Berlin, Germany) previously calibrated with ultra-purified water and physiological solution. Moreover, the $\mathrm{pH}$ value of each formulation was measured through a pH-meter (Mettler Toledo, Milano, Italy).

\subsection{Entrapment Efficiency}

In order to quantify the entrapment efficiency (EE\%) of each $\mathrm{EO}$, all formulations were centrifuged at $13,000 \mathrm{rpm}, 4^{\circ} \mathrm{C}$ for $2 \mathrm{~h}$. The separated supernatants were diluted with an ethanol-water mixture (75:25) and analyzed using a UV-vis spectrophotometer (UH5300 UV-Visible Double-Beam Spectrophotometer, Hitachi Europe, Milan, Italy). The used wavelengths were $228 \mathrm{~nm}$ for Rosmarinus EO, $230 \mathrm{~nm}$ for Mentha and Lavandula EO, and $224 \mathrm{~nm}$ for Neem oil. The calibration curves used for the quantitative evaluation of each oil were linear, considering the following ranges: $2-0.06 \mathrm{mg} / \mathrm{mL}\left(\mathrm{R}^{2}=0.9927\right)$ for Rosmarinus EO; $2-0.03 \mathrm{mg} / \mathrm{mL}\left(\mathrm{R}^{2}=0.9960\right)$ for Mentha $\mathrm{EO} ; 2-0.03 \mathrm{mg} / \mathrm{mL}\left(\mathrm{R}^{2}=0.9865\right)$ for Lavandula EO; $2-0.06 \mathrm{mg} / \mathrm{mL}\left(\mathrm{R}^{2}=0.9915\right)$ for Neem oil. Entrapment efficiency was determined using the following equation:

$$
\mathrm{EE} \%=\frac{(\text { total amount of oil used }- \text { amount of unencapsulated oil })}{\text { total amount of oil used }} \times 100
$$




\subsection{Stability Studies by Turbiscan ${ }^{\circledR}$ AG STATION}

The optical analyzer Turbiscan ${ }^{\circledR}$ Ageing Station (TAGS, Formulaction, L'Union, France) was used to assess the formulations physical stability, as it has been demonstrated to be reliable in the analysis of aggregation and/or migration instability phenomena [40-45]. In our experiment, $20 \mathrm{~mL}$ of each sample was inserted into a cylindrical glass cell, stored at $25.0 \pm 1.0{ }^{\circ} \mathrm{C}$ and analyzed for 30 days. For detailed explanation of the analyzer functioning, we remand to the literature [15]. The variation of backscattering profiles ( $\triangle \mathrm{BS}$ ) was used to compare the formulations, considering the Turbiscan ${ }^{\circledR}$ Stability Index (TSI), which numerically quantifies the formulation's stability.

\subsection{X-ray Analysis}

The assessment of X-ray diffraction of the samples was carried out with a MiniFlex Rigaku diffractometer, operating in step-scan mode and equipped with a $\mathrm{Cu} K \alpha$ source (wavelength $\lambda=0.154 \mathrm{~nm}$ ) at $30 \mathrm{kV}$ and $100 \mathrm{~mA}$. The $X$-ray diffraction data were collected in the Bragg-Brentano geometry, from 5 to $35 \mathrm{deg}$, at a scanning speed of $0.02 \mathrm{deg} / \mathrm{s}$. Crystallinity index values, related to the intensity of the peak obtained, were calculated following the equation below:

$$
\mathrm{C}=\frac{\mathrm{S}_{\mathrm{tot}}-\mathrm{S}_{\mathrm{a}}}{\mathrm{S}_{\mathrm{tot}}}
$$

where $S_{\text {tot }}$ is the total area under the graph and $S_{a}$ is the area subtended to the only amorphous region.

\subsection{Raman Spectrometry}

As previously described [15,46], Raman spectroscopy analysis was carried out using a micro-Raman spectrometer (INVIA, Renishaw, Gloucestershire, UK), which includes a $514.5 \mathrm{~nm}$ air-cooled Argon ions laser source and an 1800 lines $/ \mathrm{mm}$ grating monochromator/grid polychromator with RenCam CCD detection, with a resolution of $1 \mathrm{~cm}^{-1}$. The laser source was focused on the suspension of NLC with $100 \times$ long working objectives (a long working distance) to a stop diameter of about $1 \mu \mathrm{m}$. The acquisition time of Raman spectra varied according to the intensity of the Raman signals and lasted until a satisfactory signal-to-noise ratio was reached. Data analysis was performed by using Renishaw Wire 2.0 software. The results are reported as the mean of the intensity of 100 accumulation spectra acquired from 5 different regions, with a spatial resolution of 5 microns in each sample.

\subsection{Morphological Analysis by TEM}

In order to analyze the morphology of the produced nanoformulations, transmission electron microscopy (TEM) analysis was performed. The samples were prepared placing $5 \mu \mathrm{L}$ of each NLC on a 600-mesh carbon coated copper grid (TAAB Laboratories Equipment, Berks, UK), adding a drop of $2 \% w / v$ aqueous solution of gadolinium triacetate (Uranyl Acetate Alternative), for $2 \mathrm{~min}$, and finally drying at room temperature after the removal of the exceeding solution. The analysis was carried out through a transmission electron microscope (model HITACHI) operating at $100 \mathrm{KV}$ acceleration voltage.

\subsection{In Vitro Release Study}

Lavandula and Rosmarinus release from L-NLC and R-NLC, respectively, was evaluated by using Franz-type diffusion cells (LGA, Berkeley, CA, USA). Before being mounted in Franz-type diffusion cells, $0.75 \mathrm{~cm}^{2}$ regenerated cellulose membranes (Spectra/Por CE; Mol. Weight Cut-off $3.5 \mathrm{kDa}$ ) were moistened by immersion in water for $1 \mathrm{~h}$ at room temperature. The receptor compartment was filled with $4.5 \mathrm{~mL}$ of simulated nasal electrolytic solution (SNES) (sodium chloride $0.745 \mathrm{~g}$, potassium chloride $0.129 \mathrm{~g}$, calcium chloride dehydrated $0.005 \mathrm{~g}$, and distilled water q. s. $100 \mathrm{~mL}$ ) containing $0.5 \%$ of polysorbate 80 , to reach the sink conditions [47], thermostated at $37^{\circ} \mathrm{C}$, and constantly stirred at $600 \mathrm{rpm}$. Then, $500 \mu \mathrm{L}$ of each sample was applied in the donor compartment. The experiments were run for $48 \mathrm{~h}$. At scheduled time intervals $(0,1,2,3,4,5,6,7,8,9,24$, and $48 \mathrm{~h}), 200 \mu \mathrm{L}$ of the receptor 
medium was withdrawn and replaced with an equal volume of medium equilibrated to $37^{\circ} \mathrm{C}$. Each sample was analyzed by the UV method described in Section 2.4 to determine the EO content.

\subsection{Cytocompatibility Assay}

The cytocompatibility was assessed on two fibroblast cell lines, the NIH 3T3 mouse embryonic and the HFF1 human cell lines. NIH 3T3 and HFF1 were cultured in Dulbecco's modified Eagle's Medium (DMEM, ATCC, Manassas, VA, USA) supplemented with $10 \% \mathrm{v} / \mathrm{v}$ fetal bovine serum and $(50 \mathrm{IU} / \mathrm{mL})$ penicillin $/(50 \mathrm{\mu g} / \mathrm{mL})$ streptomycin, in a controlled environment with a temperature of $37{ }^{\circ} \mathrm{C}, 5 \% \mathrm{CO}_{2}$ concentration, and $95 \%$ relative humidity [48]. The cells were seeded in a 96-well plate $\left(1 \times 10^{4}\right.$ cells/well $)$ and incubated for $24 \mathrm{~h}$ to allow adherence. EO-NLC were diluted in DMEM in order to test different concentrations $(100,200,400$, and $500 \mu \mathrm{g} / \mathrm{mL}$ ) and the cells were treated for $24 \mathrm{~h}$. The two cell lines were also treated with DMEM medium alone, as negative control, and vehicle (Tris buffer) as positive control. The cell viability was evaluated by adding $200 \mu \mathrm{L}$ of MTT $(0.5 \mathrm{mg} / \mathrm{mL})$ in culture medium to each well and incubated for $2 \mathrm{~h}$. The optical density (OD) was measured with a microplate spectrophotometer reader (Synergy HT multi-mode microplate reader, BioTek, Milano, Italy) at $\lambda 550 \mathrm{~nm}$. The results are expressed as percentage of cell viability with respect to untreated control viable cells, whose value was equal to $100 \%$.

\subsection{Mucoadhesive Evaluation of NLC}

Positively charged NLC (L-NLC+, R-NLC+, and CT-NLC+), respectively, prepared with Lavandula, Rosmarinus, or Tegosoft CT, were obtained as previously described [49], adding $0.15 \% \mathrm{w} / \mathrm{w}$ of the cationic lipid DDAB to the oily phase. An in vitro method based on the evaluation of two parameters (zeta potential and turbidimetry) was used to assess the mucoadhesive properties of NLC. Briefly, mucin $(0.1 \% w / v)$ was suspended in PBS (pH 5.8) and stirred overnight to allow its complete dispersion. The interaction between each positively charged NLC and mucin was determined by mixing equal volumes of mucin dispersion and NLC for $15 \mathrm{~min}$ at $25{ }^{\circ} \mathrm{C}$. After 1 and $24 \mathrm{~h}$ of incubation at $37^{\circ} \mathrm{C}$, zeta potential and turbidimetric measurements were performed. In particular, turbidimetric measurements were evaluated comparing the absorbances at $650 \mathrm{~nm}$ by UV-Vis spectrophotometer of the native mucin and each dispersion.

\subsection{Statistical Analysis}

All data are reported as mean values $\pm \mathrm{SD}$. Differences, analyzed by two-sample hypothesis testing ( $t$-test), using Origin Software (version 8.5.1), were considered statistically significant for $p<0.05$. For cytocompatibility studies, statistical differences among treatments were assessed by one-way ANOVA followed by Bonferroni test.

\section{Results and Discussions}

\subsection{Physicochemical and Technological Characterization}

EO-loaded NLC for intranasal administration were produced by the PIT method, previously reported as a green technology that allows reducing the amount of surfactants and energy required [40]. All NLC were analyzed $24 \mathrm{~h}$ after their production in order to evaluate their mean size, polidispersity, zeta potential, osmolarity, $\mathrm{pH}$, and the $\mathrm{EE} \%$ of the EO. PCS results (Figure 1) show that NLC prepared with Lavandula, Mentha, or Rosmarinus showed the presence of small-sized nanoparticles of about $200 \mathrm{~nm}$ (Figure 1), therefore adequate for the intranasal route [25]. In particular, EO-loaded NLC were smaller compared to those prepared using Tegosoft CT or Neem oil, which also showed higher PDI values related to the presence of heterogeneous nanosuspensions. It is worth noting that Lavandula, Mentha or Rosmarinus favor the formation of nanoparticles with great homogeneity, as confirmed by the low PDI, a relevant parameter that strongly affects NLC feature and stability [50]. Indeed, PDI values were found to be lower than 0.3 , therefore 
related to the presence of a single peak of size distribution, in agreement with previous data [4].
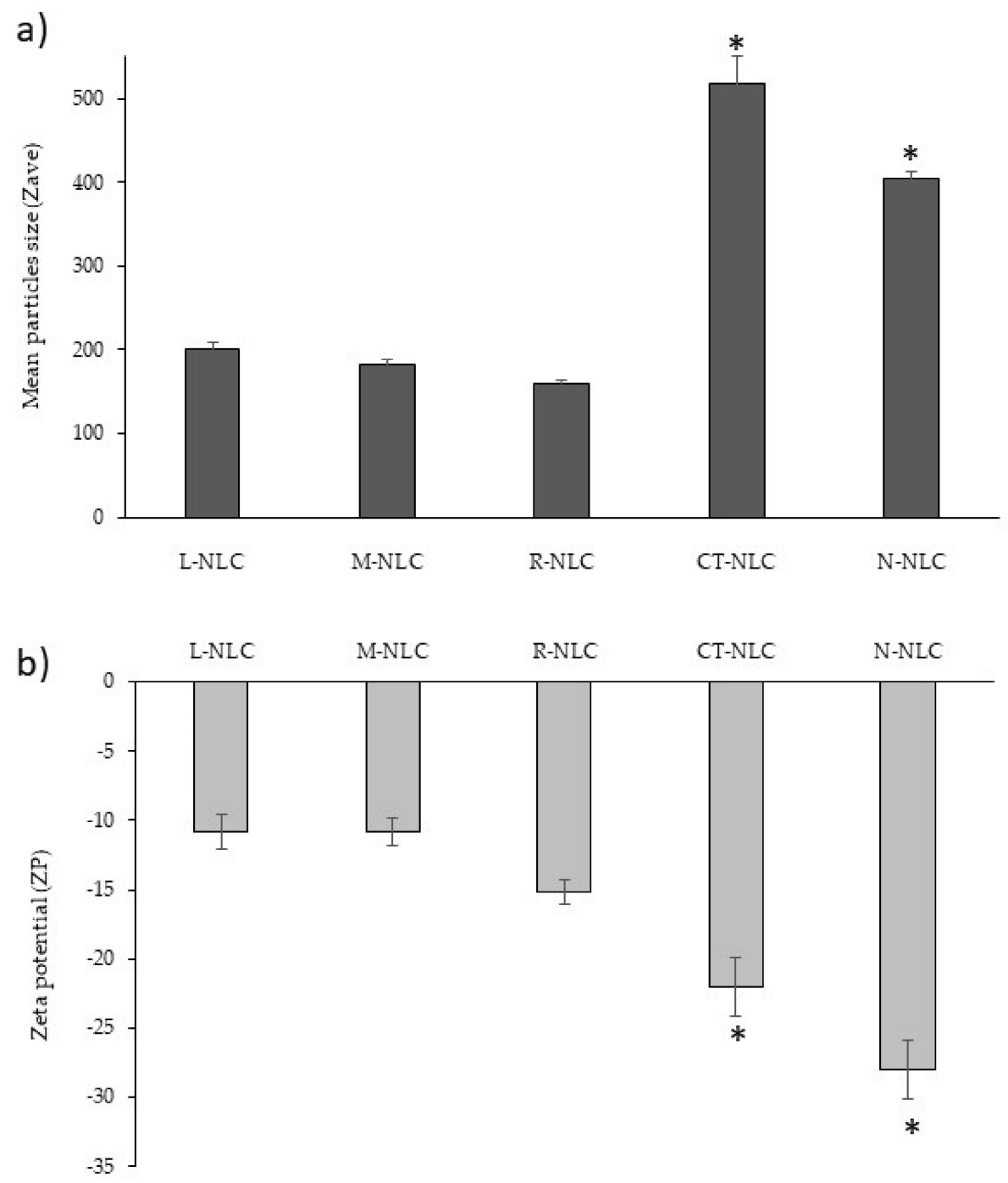

Figure 1. (A) Mean particle size (Zave, nm) and (B) Zeta Potential (ZP) \pm standard deviation (SD) of the prepared Lavandula NLC (L-NLC), Mentha NLC (M-NLC), Rosmarinus NLC (R-NLC), Tegosoft CT NLC (CT-NLC) and Neem NLC (N-NLC). * Significance for $p<0.05$, comparison between EO-loaded NLC (L-NLC, M-NLC, and R-NLC) and the control NLC (CT-NLC and N-NLC).

In order to ensure the formulation's safety on cell functioning, viability, and stability, without potential damages and alterations due to water movements through the membranes, it is important that NLC osmolarity and $\mathrm{pH}$ values are kept in the physiological range [51]. As reported in Table 1, osmolarity values of the produced NLC were in the range 291-299 mOsm $/ \mathrm{kg}$. In addition, $\mathrm{pH}$ measurements showed that $\mathrm{pH}$ values were in the physiological range for all nanosuspensions, with values between 7.09 and 7.28 for all formulations. It is interesting to highlight that Lavandula, Mentha, and Rosmarinus showed significantly higher EE\% values compared to Neem oil (Table 1). As expected, a certain loss of EO was observed, due to the presence of micelles of surfactants, which do not participate in the formation of nanoparticles. For this reason, each system was further analyzed after the purification step. 
Table 1. Values of $\mathrm{pH}$, osmolarity, and entrapment efficiency (EE\%) \pm standard deviation (SD) of NLC prepared with Lavandula (L-NLC), Mentha (M-NLC), Rosmarinus (R-NLC), Tegosoft CT (CT-NLC), and Neem (N-NLC).

\begin{tabular}{cccc}
\hline Sample & $\mathbf{p H} \pm \mathbf{S D}$ & $\begin{array}{c}\text { Osmolarity } \\
\text { (mOsm/kg } \pm \text { SD) }\end{array}$ & EE\% \pm SD \\
\hline L-NLC & $7.13 \pm 0.5$ & $299.5 \pm 0.1$ & $76.47 \pm 0.8$ \\
M-NLC & $7.19 \pm 0.6$ & $293.1 \pm 0.3$ & $67.15 \pm 0.3$ \\
R-NLC & $7.20 \pm 0.5$ & $291.0 \pm 0.5$ & $64.09 \pm 0.9$ \\
CT-NLC & $7.28 \pm 0.7$ & $297.9 \pm 0.2$ & $100.00 \pm 0.0$ \\
N-NLC & $7.09 \pm 0.4$ & $291.5 \pm 0.7$ & $19.61 \pm 0.8$ \\
\hline
\end{tabular}

These findings, in agreement with PCS results, would suggest a better organization of the raw materials at the interface when using the three EOs, as also suggested by the smaller particles obtained for L-NLC, M-NLC, and R-NLC.

As shown in Figure 1, all samples were negatively charged $(\approx-20 \mathrm{mV})$, without significant differences related to the oil, even if the presence of Neem oil induced a slight increase in ZP value, confirming literature findings [52]. As reported in the literature [53], high ZP values would suggest a long-term physical stability of the colloidal suspension, due to nanoparticles' repulsions.

In order to deepen the NLC stability, a key parameter for nano-sized colloids [50], we exploited Turbiscan ${ }^{\circledR}$ technology, storing samples for 30 days at $25{ }^{\circ} \mathrm{C}$. Interestingly, the instability kinetics obtained by TSI values, as reported in Table 2 , showed that NLC prepared with the three EOs were more stable compared to CT-NLC, which showed a significant increase already after 3 weeks of storage. In particular, the following decreasing scale of stability can be described as follows: L-NLC $=$ R-NLC $\geq$ N-NLC $\geq$ M-NLC $>>$ CT-NLC. Therefore, NLC prepared with Lavandula and Rosmarinus showed a greater stability compared to other samples, probably due to the smaller mean size and the higher homogeneity of the nanoparticles in suspensions. Among all the prepared formulations, the use of the commercial oil CT reduced the colloidal suspension's stability, as confirmed by the backscattering variation reported in Figure 2a. Herein, significant instability phenomena related to both particle migration and aggregation occurred ( $\triangle \mathrm{BS} \geq 20 \%$ ).

The greater stability of L-NLC and N-NLC was confirmed by the absence of significant variation in BS profiles, as resulted by the low values registered, related to slight particle migration at the bottom of the cuvette (Figure 2b,c). R-NLC and M-NLC showed similar profiles to those reported for L-NLC and N-NLC, respectively (data not reported).

The stability results are in agreement with PCS measurements of samples analyzed after 28 days of storage, showing that, at the 0.05 level of significance, the difference between the population mean size and PDI was significantly different for mean size only for CT-NLC, whose particles were found to be of about $500 \mathrm{~nm}$ (Figure S1). These data are in agreement with previous findings, with L-NLC showing a more stable long-term behavior thanks to the tendency of the nanoparticles to agglomerate, thus determining the formation of a flocculated suspension, whose nanoparticles can be easily dispersed by gentle shaking.

Table 2. Turbiscan Stability Index (TSI) of NLC analyzed for 30 days at $25^{\circ} \mathrm{C}$ using Turbiscan ${ }^{\circledR}$ Aging Station. ${ }^{*}$ Significance for $p<0.05$.

\begin{tabular}{cccccc}
\hline \multirow{2}{*}{ Sample } & \multicolumn{5}{c}{ Day of the Measurement } \\
\cline { 2 - 6 } & Day 1 & Day 7 & Day 14 & Day 21 & Day 28 \\
\hline CT-NLC & 0.42 & 2.28 & 6.03 & $8.60^{*}$ & $11.16^{*}$ \\
L-NLC & 0.38 & 1.73 & 2.39 & 3.14 & 5.99 \\
R-NLC & 0.37 & 1.74 & 2.33 & 3.02 & 5.96 \\
M-NLC & 0.40 & 1.62 & 3.98 & 5.28 & $7.02 *$ \\
N-NLC & 0.40 & 1.61 & 3.86 & 5.15 & 6.52 \\
\hline
\end{tabular}




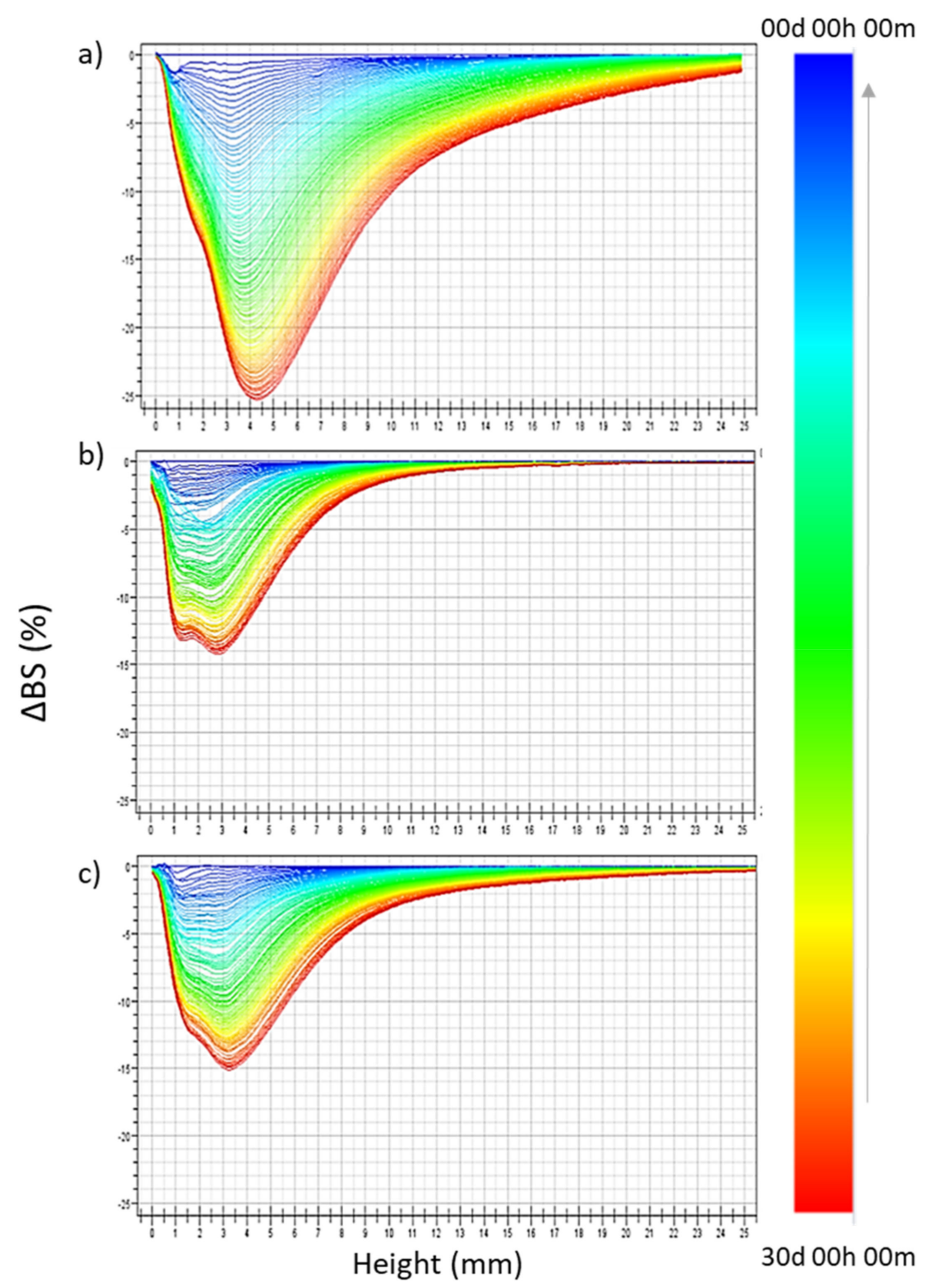

Figure 2. Backscattering profiles ( $\triangle \mathrm{BS})$ of CT-NLC (a), L-NLC (b), and N-NLC (c) stored in Turbiscan ${ }^{\circledR}$ for 30 days at a temperature of $25.0 \pm 1.0^{\circ} \mathrm{C}$. Data are presented as a function of time (0-30 days) of sample height ( 0 to $20 \mathrm{~mm}$ ) (the direction of analysis time is indicated by the arrow).

In order to analyze the influence of the oily component on the NLC structure, Xray diffraction, Raman spectroscopy, and Transmission Electron Microscopy (TEM) were performed. In particular, NLC were analyzed through Raman spectroscopy using a microRaman spectrometer, in order to obtain the so-called "molecular footprint" of the sample, which provides information about the sample's molecular composition and structure [54]. In particular, through molecular vibrations produced by a laser beam, a map of chemical and structural changes in molecules can be obtained, which describes conformation and arrangement in lipid chain after the addition of the oil [55]. Since a similar behavior was observed for NLC produced using Neem oil or Mentha EO compared to NLC prepared using Lavandula or Rosmarinus EO, for a clearer representation of data, we report only L-NLC and N-NLC Raman spectra vs. CT-NLC (Figure 3). The Raman spectra of all the prepared NLC are reported in Figure S2. Although no shifts in the frequencies of the Raman transitions arise in a comparison of the different samples, the relative intensities in significant regions change conspicuously for L-NLC compared to controls, CT-NLC and N-NLC (Figure 3). 


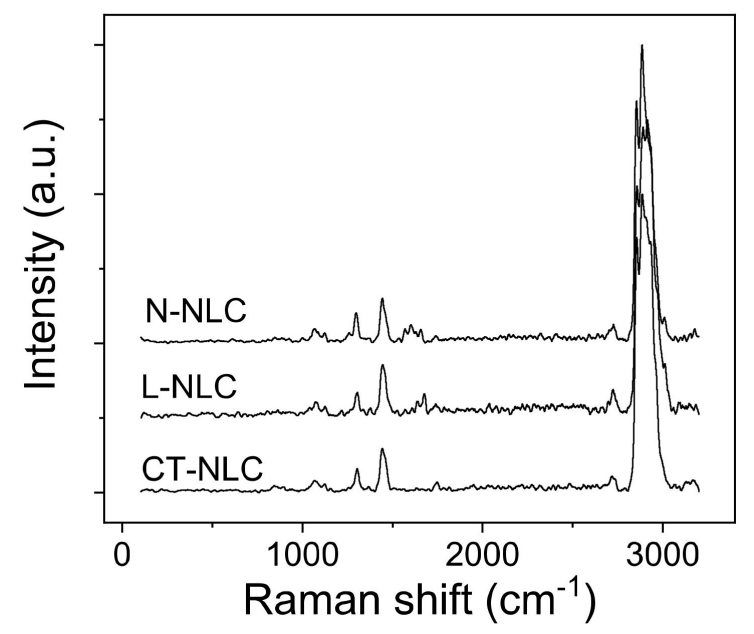

Figure 3. Raman spectra of L-NLC, CT-NLC, and N-NLC.

The most intense bands in the spectra of molecules including alkanes and lipids with alkyl groups are the $\mathrm{CH}$ stretching modes. The most common vibrational Raman active modes in the analyzed systems are summarized in Table 3. Both frequency differences and relative intensity changes for these vibrational modes have been used to monitor specific conformational changes in the hydrocarbon chains [56]. The $1100 \mathrm{~cm}^{-1}$ region in particular has been shown to be a superposition of the C-C stretching modes for segments of all-trans hydrocarbon conformations.

Table 3. Common vibrational modes.

\begin{tabular}{cc}
\hline Functional Group Mode & Approximate Wave Number $\left(\mathbf{c m}^{-\mathbf{1}}\right)$ \\
\hline$-\mathrm{CH}_{3}$, symmetric and antisymmetric stretch & $2920-2960$ \\
$-\mathrm{CH}_{3}$, symmetric and antisymmetric stretch & $2850-2890$ \\
$-\mathrm{PO}_{2}$, symmetric and antisymmetric stretch & $1080-1200$ \\
$-\mathrm{C}-\mathrm{C}-$ & $1050-1150$ \\
$-\mathrm{C}-\mathrm{O}-$ & 1410 \\
$-\mathrm{C}=\mathrm{O}$ & 1720 \\
$-\mathrm{COH}$ & $870-890$ \\
$-\mathrm{OH}$ & $1080-1090$ \\
$-\mathrm{CH}_{2-}$, deformation & $1460-1470$ \\
\hline
\end{tabular}

An increase in intensity of the $1115 \mathrm{~cm}^{-1}$ band relative to the intensities of the $1050 \mathrm{~cm}^{-1}$ transitions $\left(\mathrm{I}_{1115} / \mathrm{I}_{1050}\right)$ is indicative of a greater fluidity within the hydrocarbon chains; therefore, the increase in the $1115 \mathrm{~cm}^{-1}$ band originates from the increased intramolecular disorder in the systems. The Raman spectra of the NLC systems in the 2750-3050 $\mathrm{cm}^{-1}$ spectral region, i.e., the C-H stretching vibration region, are well fitted as a sum of six Gaussian bands, as reported in the Table S1. It is well known that lipids interact with phospholipidic membrane. De Lange et al. [57] reported that Raman spectra of binary vesicles-cholesterol bilayers showed little variation associated with cholesterol, which allows spectral changes to be assigned to the lipid-chain vibrational signatures of the liquid-disordered (1-d), solid-ordered (s-o), and liquid-ordered (1-o) phases. Analyzing the $\mathrm{C}-\mathrm{H}$ stretching, $\mathrm{C}=\mathrm{O}$ stretching, and $\mathrm{CH}_{2}$ bending modes, it is possible to monitor the structural order evolution of cholesterol in vesicle systems [58]. The region around $3000 \mathrm{~cm}^{-1}$ of the Raman spectrum consists of a large number of overlapping peaks, containing both fundamental $\mathrm{CH}$-stretch vibrations and Fermi resonance bands. The $\mathrm{CH}_{3}$ symmetric stretching modes appear in the $2870-2880 \mathrm{~cm}^{-1}$ spectral region, with a Fermi resonance (FR) component in the $2930-2940 \mathrm{~cm}^{-1}$ region. The peaks in the $2950-2970 \mathrm{~cm}^{-1}$ spectral region are the $\mathrm{CH}_{3}$ out-of-plane and in-plane methyl antisymmetric stretches. The methylene vibrations at approximately 2850, 2880, 2900, and $2930 \mathrm{~cm}^{-1}$ are sensitive to 
conformational changes as well as intermolecular interactions of the alkyl chains of lipids. The $\mathrm{va}\left(\mathrm{CH}_{2}\right)$ antisymmetric stretch is coupled to rigid rotations-torsional vibrations, so that it broadens considerably with temperature, and increases continuously in frequency, from 2880 to $2900 \mathrm{~cm}^{-1}$, as gauche conformers are introduced. The $v \mathrm{~s}\left(\mathrm{CH}_{2}\right)$ symmetric stretch contains three components, centered at 2852, 2900, and $2928 \mathrm{~cm}^{-1}$, because of extensive Fermi resonance interactions with overtones of the bending modes, and it is affected by intra- and inter-molecular interactions. The relative intensities of the peaks in this last spectral region change notably with changes in hydration state, packing, and conformational order $[57,58]$. In order to exploit this spectral sensitivity toward the lipid environment, several spectral parameters have been used in the literature that empirically describe the order of the lipid matrix. The peak height ratio $\mathrm{I}_{2890} / \mathrm{I}_{2850}$ has been used as a marker for chain packing and conformational disorder, where higher values indicate a higher ordering of the chains [59]. Table 4 resumes the Raman intensity ratios related to C-C stretching vibrational bands $\left(\mathrm{I}_{1115} / \mathrm{I}_{1050}\right)$ and C- $\mathrm{H}$ stretching vibrational bands $\mathrm{I}_{2890} / \mathrm{I}_{2850}$ for all samples.

XRD measurements were performed for all NLC, showing a similar behavior between Lavandula, Mentha and Rosmarinus with respect to the controls CT-NLC and N-NLC. Figure 5 shows the XRD spectra recorded for L-NLC vs. control NLC samples. The presence of discrete peaks, more or less pronounced, emerging from a very large peak is evident in each spectrum. This indicates that the observed material is characterized by a semi-crystalline structure. The discrete peaks (labeled 1-4) correspond to the interplanar spacings of $1.22,0.46,0.42$, and $0.38 \mathrm{~nm}$, respectively. These four peaks are clearly visible for L-NLC. M-NLC and R-NLC showed similar XRD spectra to that of L-NLC (Figure S3). Contrarily, CT-NLC and N-NLC showed a considerably reduced intensities of Peaks 2 and 3. The occurrence of such peaks indicates the presence of ordered solid lipids in the $\beta$ and $\beta^{\prime}$ crystallographic modifications [60]. In addition, in Figure 4, it is evident that the relative intensity of the various peaks is different for each sample: the peaks are well pronounced in all EO-loaded NLC, as reported for L-NLC (Figure 5), but are very low in the controls CT-NLC and N-NLC.

Table 4. Raman intensity ratios related to $\mathrm{C}-\mathrm{C}$ stretching vibrational bands $\left(\mathrm{I}_{1115} / \mathrm{I}_{1050}\right)$ and C-H stretching vibrational bands $\mathrm{I}_{2890} / \mathrm{I}_{2850}$.

\begin{tabular}{ccc}
\hline Sample & $\mathbf{I}_{\mathbf{1 1 1 5}} / \mathbf{I}_{\mathbf{1 0 5 0}}$ & $\mathbf{I}_{\mathbf{2 8 9 0}} / \mathbf{I}_{\mathbf{2 8 5 0}}$ \\
\hline CT-NLC & 0.69 & 1.20 \\
L-NLC & 0.74 & 1.94 \\
M-NLC & 0.53 & 0.50 \\
N-NLC & 0.71 & 0.62 \\
R-NLC & 0.67 & 1.00 \\
\hline
\end{tabular}

The Raman spectra of L-NLC, CT-NLC, and N-NLC systems in the C-H stretching vibration region are shown in Figure 4. The spectrum in the $2750-3050 \mathrm{~cm}^{-1}$ spectral region is well fitted as a sum of six Gaussian bands, as reported in the Supplementary Materials. 


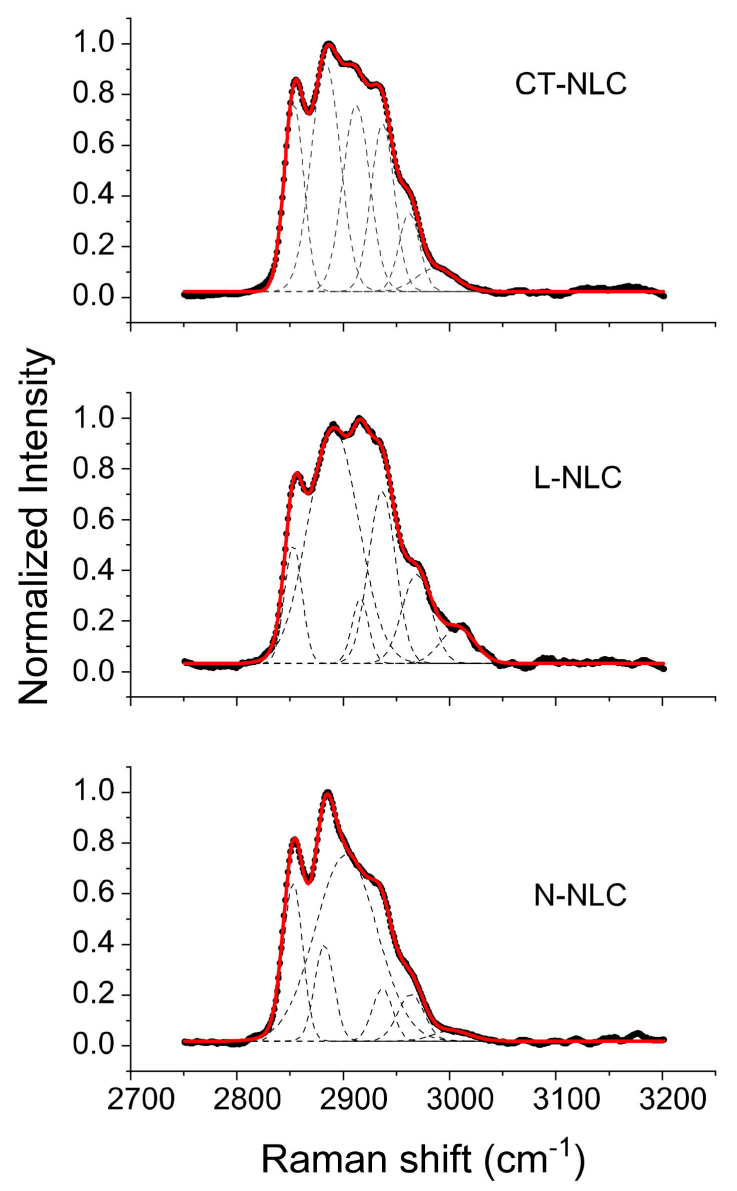

Figure 4. Raman spectra of NLC prepared with Lavandula (L-NLC), Tegosoft CT (CT-NLC), and Neem oil (N-NLC): region around $3000 \mathrm{~cm}^{-1}$.

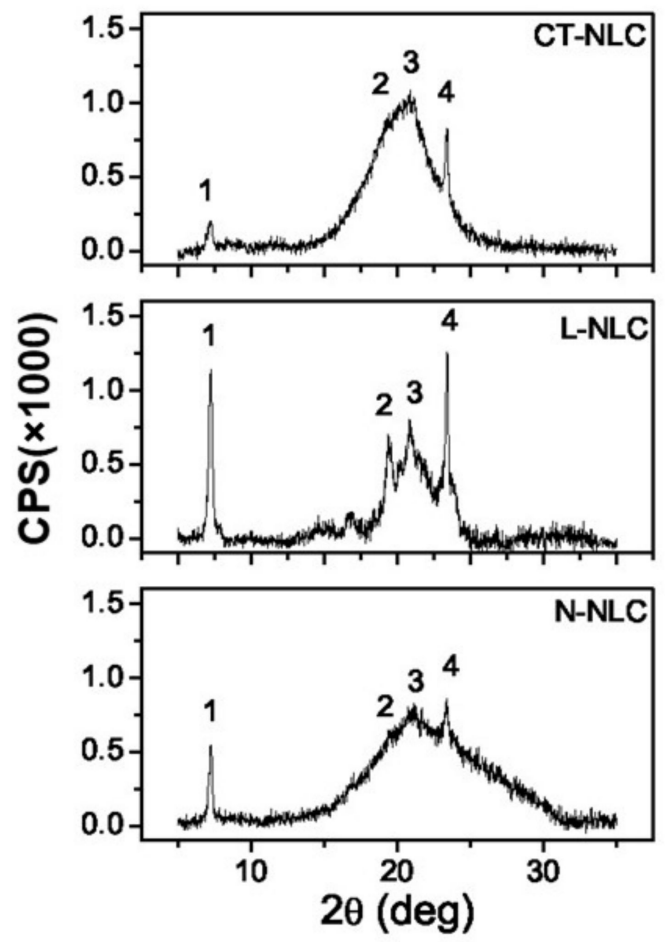

Figure 5. XRD spectra of representative samples L-NLC, CT-NLC, and N-NLC. 
Through X-ray diffraction, it was possible to measure the NLC crystallinity index (C), an important parameter that allows predicting polymorphic transitional changes during storage [55]. Crystallinity was measured between 5 and 30 degrees, and the obtained results are reported in Table 5. Comparing the NLC produced with different EOs, it emerged that the use of Lavandula and Rosmarinus led to the formation of NLC with the highest values of crystallinity (68\% and 40\%, respectively), while NLC prepared using Mentha or Neem oil showed lower values (30\% and $20 \%$, respectively). It is possible that the high amount of linalool present in the complex mixture of Lavandula and Rosmarinus increases the NLC stability, as we previously reported [4]. Interestingly, the lowest crystallinity value (10\%) was registered for CT-NLC, related to the presence of a less ordered structure. As reported in the literature, the crystallinity of the lipid matrix is affected by the structure of the liquid oil [61]. Therefore, the following scale based on the reduction of the crystallinity value can be described: L-NLC > R-NLC > M-NLC > N-NLC > CT-NLC. The lowest crystallinity found for caprylic/capric triglyceride is consistent with literature findings, in which the addition of a synthetic oil was demonstrated to strongly reduce the crystallinity of the lipid matrix [61,62]. It is interesting to highlight that the crystallinity scale presents the same order of the stability scale obtained by Turbiscan ${ }^{\circledR}$ analysis, with L-NLC and R-NLC as the most stable formulations compared to other NLC.

Table 5. Crystallinity (C\%) of Tegosoft CT NLC (CT-NLC), Neem NLC (N-NLC), Mentha NLC (M-NLC), Lavandula NLC (L-NLC), and Rosmarinus NLC (R-NLC).

\begin{tabular}{cc}
\hline Sample & C (\%) \\
\hline CT-NLC & $10 \%$ \\
N-NLC & $15 \%$ \\
M-NLC & $30 \%$ \\
L-NLC & $68 \%$ \\
R-NLC & $40 \%$ \\
\hline
\end{tabular}

In order to analyze the NLC morphology, TEM analysis was performed. Figure 6 reports TEM images of L-NLC, CT-NLC and N-NLC. In particular, CT-NLC (Figure 6a,b) showed a very irregular arrangement of nanoparticles, with a central oily core and a large shell. N-NLC (Figure 6c,d) and M-NLC (Figure S4) showed the presence of a faint central oily core surrounded by the solid lipid and surfactants layers, in agreement with previous studies $[63,64]$. On the other side, L-NLC (Figure 6f) and R-NLC (Figure S5) showed a structure characterized by the presence of many oily droplets dispersed in the solid lipid matrix, in agreement with previous findings [65]. It is possible that the ability of Lavandula and Rosmarinus to create imperfections in the NLC matrix also affects the nanoparticles' structure, improving their order and, consequently, stability during storage, probably due to their composition characterized by high amount of linalool $[4,15,16]$.

As reported in Figure 7, the release profiles of EOs from NLC was similar for Lavandula and Rosmarinus, with a sustained release over the first $8 \mathrm{~h}$, with about $20 \%$ of EO released from NLC. After 24 and $48 \mathrm{~h}$, the cumulative amount of EO reached about $50 \%$ and $80 \%$ of the loaded oil, respectively (Figure 7). Our results are in agreement with previous findings [66], confirming the advantages of EO encapsulation into NLC that would provide a sustained and prolonged release. 


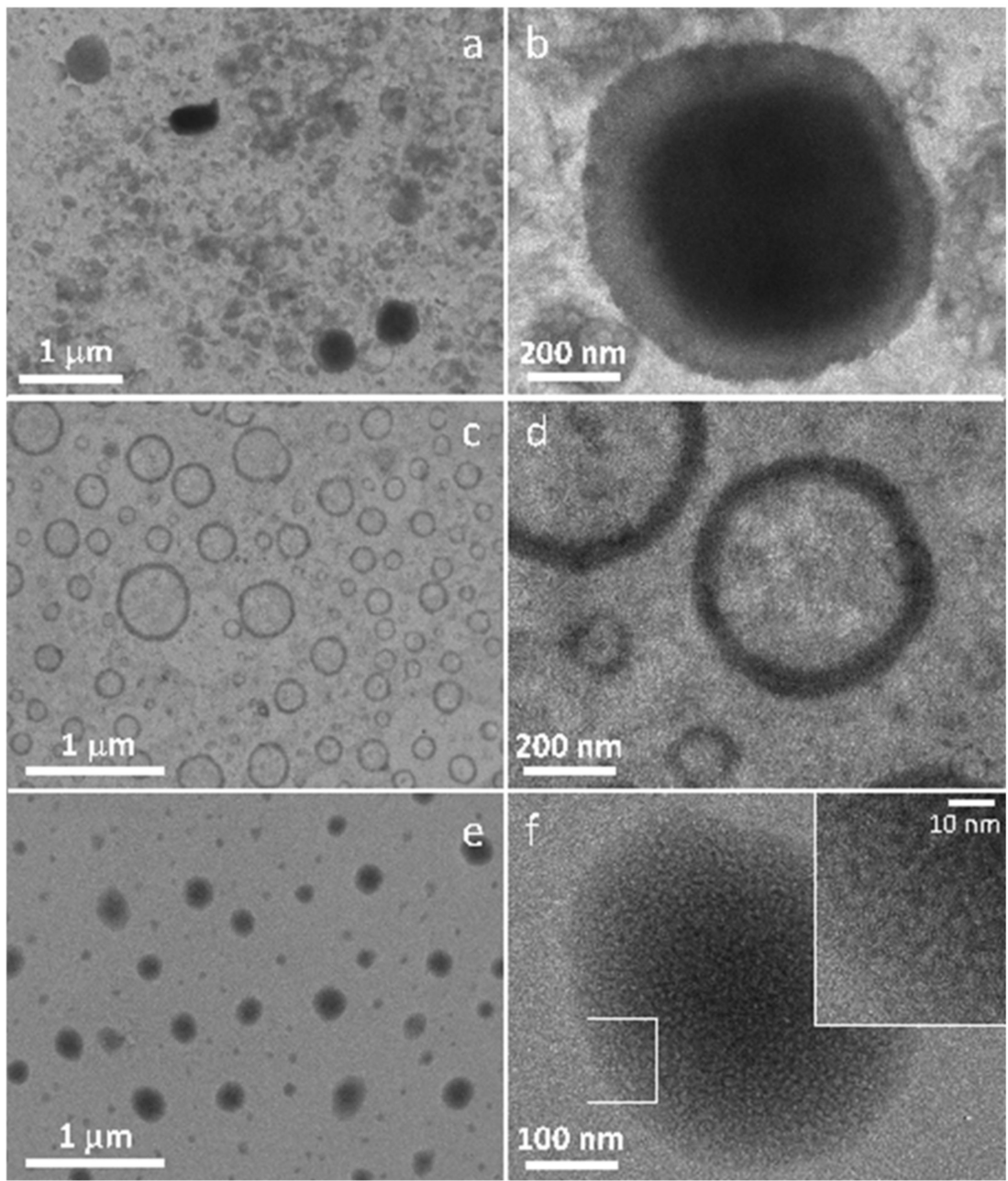

Figure 6. Transmission electron microscopy (TEM) images of: CT-NLC (a,b); N-NLC (c,d); L-NLC (e,f).
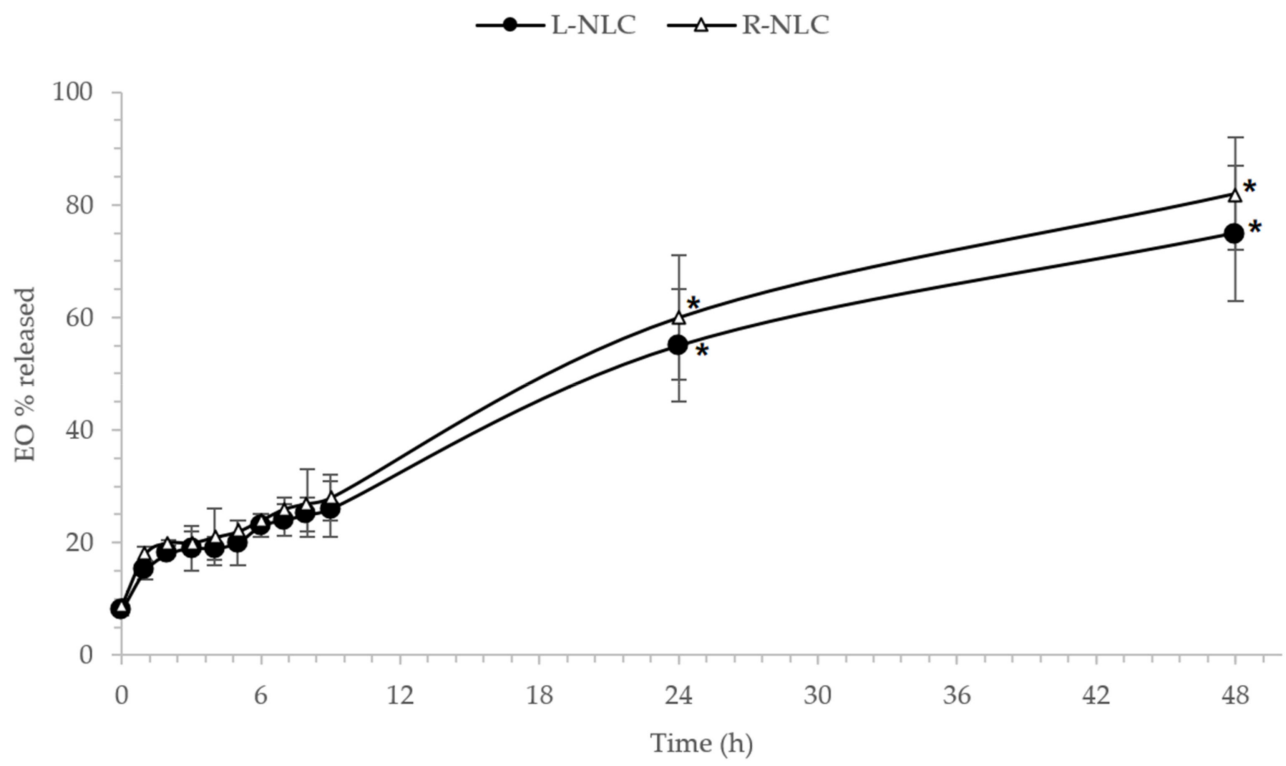

Figure 7. Percentage of Lavandula and Rosmarinus EOs released from L-NLC and R-NLC, respectively, at different time intervals up to $48 \mathrm{~h}$. Each value is the mean of six independent experiments. * Significance for $p<0.05$. 


\subsection{In Vitro Cytocompatibility}

3-(4,5-dimethylthiazol-2-yl)-2,5-diphenyltetrazolium bromide (MTT) assay was performed in order to assess NLC cytocompatibility. Some NAD(P)H-dependent oxidoreductase enzymes are produced by living cells and are able to cause the conversion of yellow MTT salt into purple formazan. The intensity of the color is directly related to the cells viability; quantification of formazan crystals is carried out through absorbance measurement. MTT assay was performed on human (HFF1) and murine (NIH-3T3) fibroblast cell lines, selected to test the biocompatibility and safety of NLC nanosuspensions, which is essential to ensure that the NLC do not affect the capability of normal cells to produce trophic growth factor, which support a variety of cellular processes of the above epithelial tissues [67]. All the prepared NLC were tested at different concentrations $(100,200,400$, and $500 \mu \mathrm{g} / \mathrm{mL}$ ) and compared to controls. The results are reported in Figures 8 and 9.

As expected, the control formulation prepared using Tegosoft CT (CT-NLC), did not affect cell viability of both murine and human fibroblasts, showing a cell viability higher than $90 \%$ at all tested concentrations. No cytotoxic effects were observed when murine fibroblasts were treated with N-NLC, while the highest concentration $(500 \mu \mathrm{g} / \mathrm{mL})$ significantly reduced human fibroblast viability by a hefty $60 \%$. This result is supported by previous studies showing Neem cytotoxic effects on different cell lines (embryonic 3T3 fibroblasts, HeLa tumor cells, HaCat keratinocytes, and V79-4 pulmonary fibroblasts) when used at low concentration and in combination with oleic acid [63]. Furthermore, Neem oil was found to induce cell death in a time-dependent manner on HCT116 cells, whose effect was attributed to the cell cycle arrest and apoptosis due to Neem limonoids, even if the molecular mechanism of Neem limonoid-induced cell death has not been described [68]. Interestingly, L-NLC and R-NLC showed good biocompatibility on both murine and human cell lines, at all tested concentrations. This result is consistent with previous studies demonstrating that the EO encapsulation is able to improve the oil biocompatibility on Raw 264.7 cells (macrophage cell line) [4]. Mentha EO-loaded NLC (M-NLC) showed a dose-dependent effect, since concentrations equal to 100 and $200 \mu \mathrm{g} / \mathrm{mL}$ resulted to be highly biocompatible, while a 50\% reduction in fibroblasts viability was observed at 400 and $500 \mu \mathrm{g} / \mathrm{mL}$. This result is consistent with earlier research, in which Mentha species EOs have been reported to exert cytotoxic effects that can be exploited to treat cancer, due to their ability to inhibit the cell proliferation of numerous tumor cells by acting on mitochondrial dysfunctions, apoptosis induction, and autophagy processes $[69,70]$.

Based on the obtained results, Lavandula and Rosmarinus were selected as safe and promising EOs to be encapsulated into NLC for the potential treatment of Alzheimer's disease, thanks to the formation of small and homogeneous particles and a more ordered structure related to the formation of oily droplets into the lipid matrix. In order to exploit the intranasal delivery, we aimed at improving the mucoadhesive properties of the systems, with the addition of a coating layer of the cationic lipid DDAB, thus obtaining L-NLC+, R-NLC+, and CT-NLC+, respectively, prepared with Lavandula, Rosmarinus, and Tegosoft CT. DDAB at $150 \mu \mathrm{g} / \mathrm{mL}$ was selected as a safe concentration able to guarantee positive $\mathrm{ZP}$ value. As recently reported, DDAB is safe on human keratinocytes (HaCaT) and osteoblast-like (SAOS-2) cell lines, with cell viability being higher than $90 \%$ of control at $165 \mu \mathrm{g} / \mathrm{mL}$ and higher than $50 \%$ for twice this concentration $(330 \mu \mathrm{g} / \mathrm{mL})$ [71]. As expected, the addition of such a low amount of the positively charged coating layer did not induce significant modification in mean size, whose values were found to be 211.1 and $184.5 \mathrm{~nm}$ for L-NLC and R-NLC, respectively, without affecting PDI $(<0.3)$. ZP was found to be highly positive, with values equal to +40.5 and $+43.0 \mathrm{mV}$ for L-NLC and R-NLC, respectively. In order to verify the mucoadhesive properties of L-NLC+ and R-NLC+, compared to the control CT-NLC+, the interaction with mucin was evaluated over a period of $24 \mathrm{~h}$, by measuring the turbidity at $650 \mathrm{~nm}$ (ABS) and the change in the $\mathrm{ZP}$ values (Figure 10). 


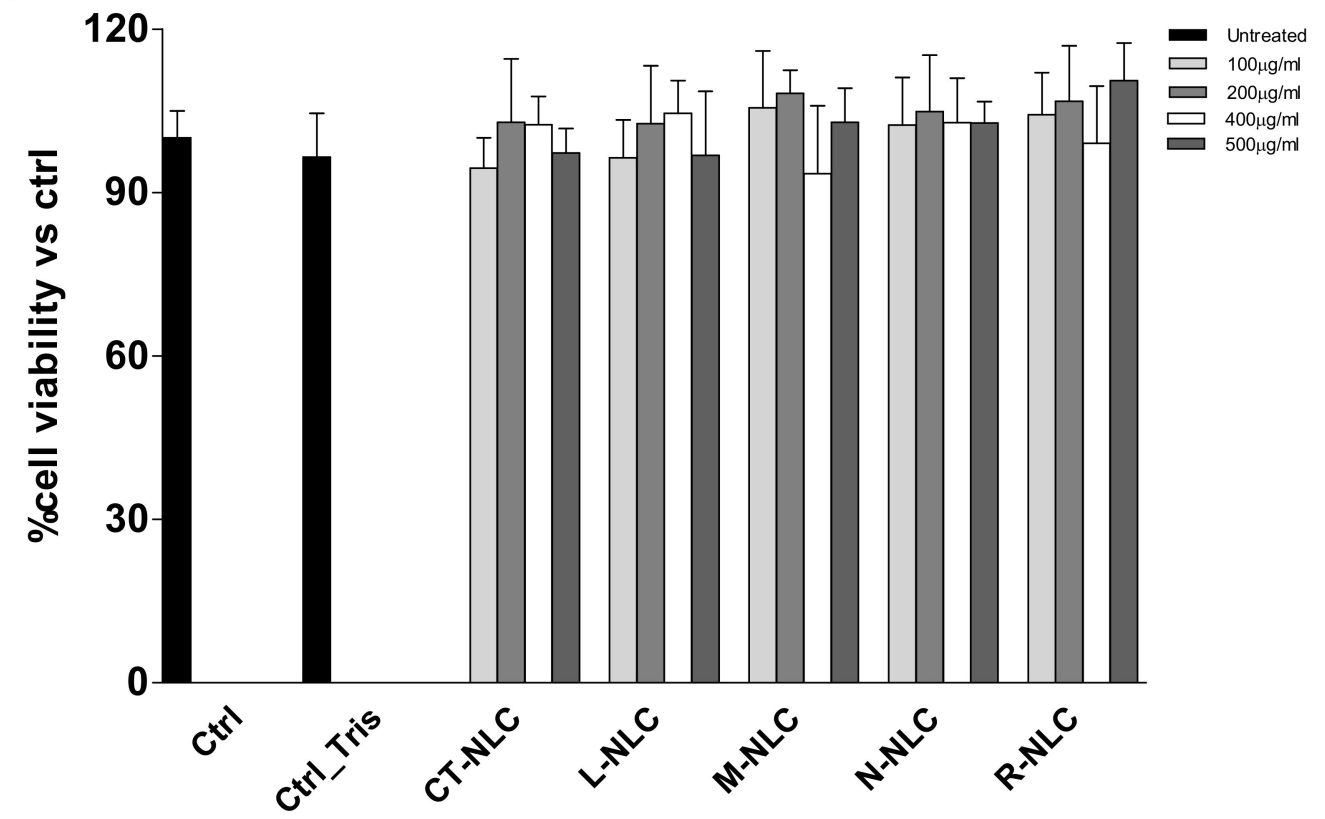

Figure 8. Murine fibroblasts NIH-3T3 viability after $24 \mathrm{~h}$ treatment with different concentrations of Tegosoft CT NLC (CT-NLC), Lavandula NLC (L-NLC), Rosmarinus NLC (R-NLC), Mentha NLC $(\mathrm{M}-\mathrm{NLC})$, and Neem NLC (N-NLC). All values are mean $\pm \mathrm{SD}$ of three experiments in triplicate.

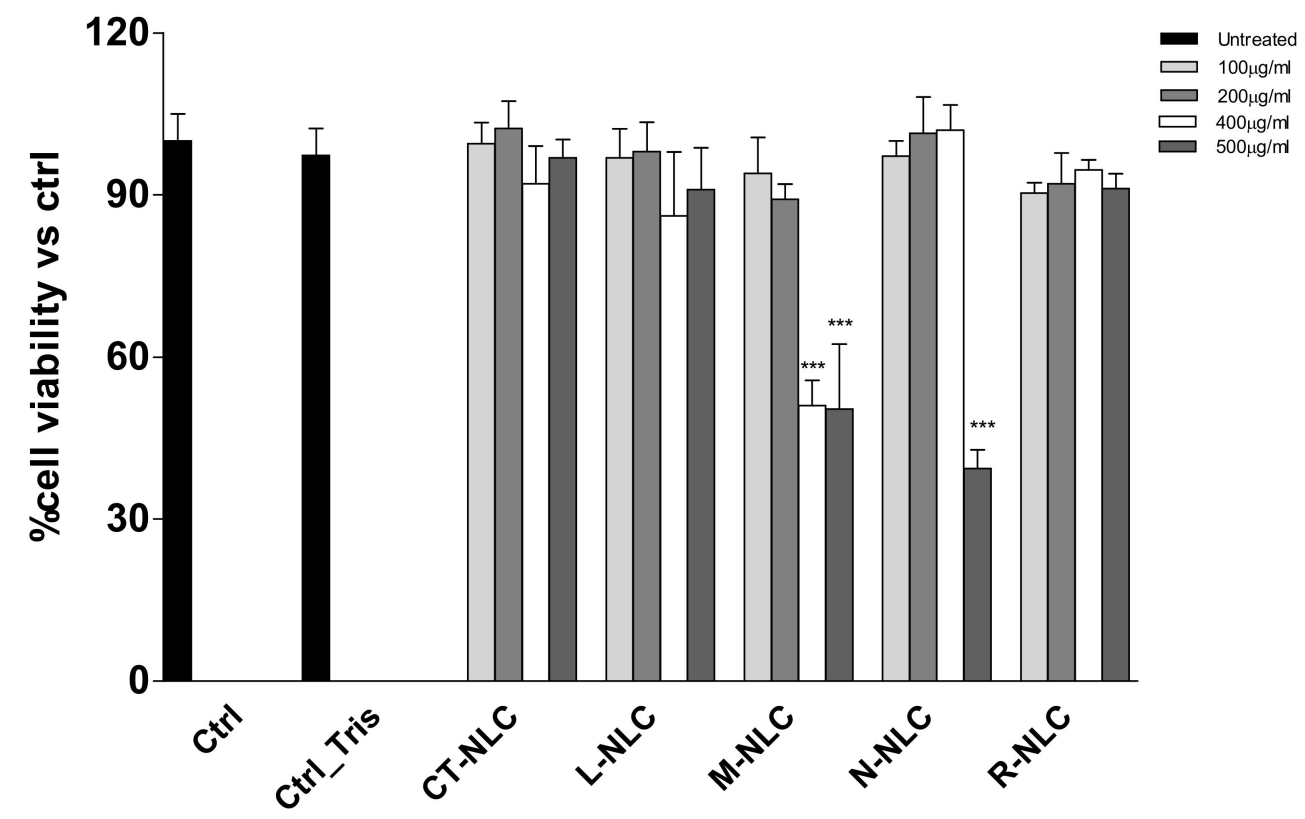

Figure 9. Human fibroblasts HFF1 viability after $24 \mathrm{~h}$ treatment with different concentrations of Tegosoft CT NLC (CT-NLC), Lavandula NLC (L-NLC), Rosmarinus NLC (R-NLC), Mentha NLC $(\mathrm{M}-\mathrm{NLC})$, and Neem NLC (N-NLC). All values are mean $\pm \mathrm{SD}$ of three experiments in triplicate. *** $p<0.001$ vs. control. 
A

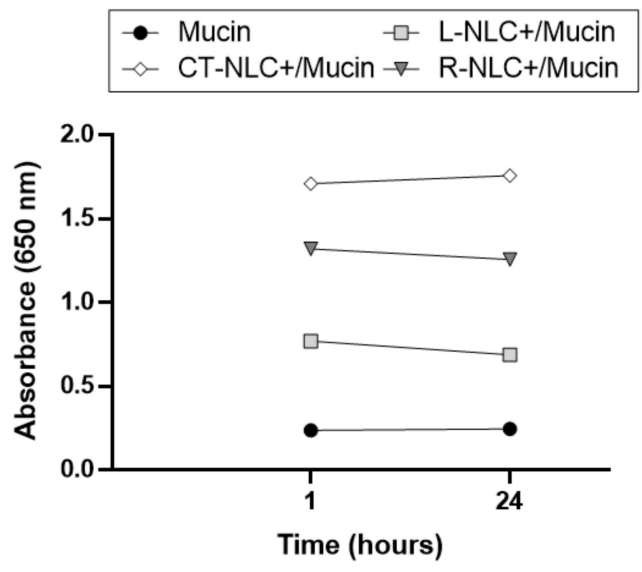

B

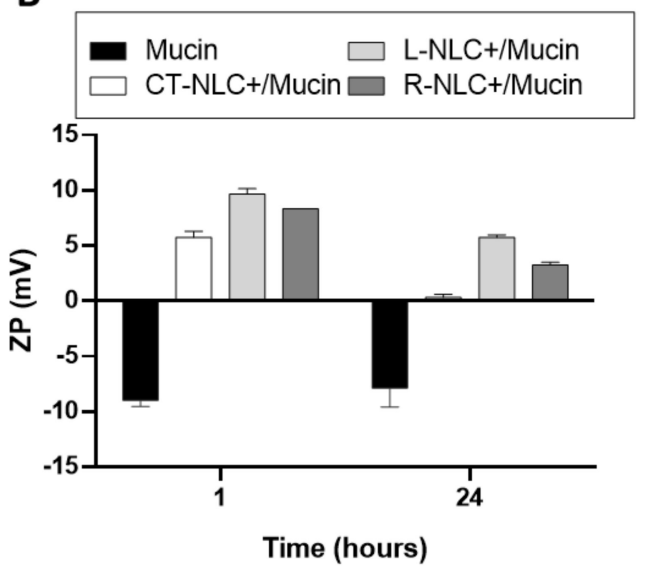

Figure 10. In vitro assessment of mucin interactions with CT-NLC+, R-NLC+, and L-NLC+ by turbidimetric assay at $650 \mathrm{~nm}(\mathrm{~A})$ and Zeta potential (ZP) modifications (B).

Absorbance measurement was reported to give a rough estimation of particle-mucin interaction [72]. The mucoadhesive interaction between particles and mucin results in the adsorption of the mucin around the surface of the particles with a consequent slight aggregation that can be detected as an increase in UV absorbance [73]. For this reason, the turbidity value after mixing CT-NLC+, R-NLC+, and L-NLC+ with native mucin was determined after $1 \mathrm{~h}$ and followed up to $24 \mathrm{~h}$. As shown in Figure 10A, the turbidity of all $\mathrm{NLC}+$ /mucin dispersions was higher than the turbidity of mucin dispersion itself at both the time points considered, thus suggesting the interaction between NLC+ and mucin [74]. Furthermore, high absorbance values of CT-NLC+, R-NLC+, and L-NLC+ dispersions before incubation with mucin (whose values were 2.015, 1.226, and 2.049, respectively) reflected particle motion [72], while reduced values after their incubation with mucin (Figure 10A) are related to possible particle immobilization due to adsorption of mucin on their surface [75]. As reported by D'Angelo et al., mucin's adsorption on particle surface is expected to reduce particle mobility, agglomeration, and to a certain extent precipitation might take place [76]. Our results suggest higher interactions for both nanosystems with EO compared to the CT-NLC+.

Particle-mucin interactions were further confirmed by ZP measurements. Important changes in $\mathrm{ZP}$ value are related to strong mucoadhesive properties. In our previous study, the interaction between mucin and PLGA-PEG nanoparticles (NPs) intended for intranasal administration was evaluated [77]. Herein, ZP of PLGA-PEG NPs remained almost unchanged in the presence of mucin, demonstrating that weak interactions occurred between PEGylated NPs and mucin [77].

In the present study, upon addition of CT-NLC+, R-NLC+, and L-NLC+ to mucin, the negative $\mathrm{ZP}$ of mucin $(\sim-9 \mathrm{mV})$ was inverted to a positive value (Figure 10B), and consequently a significative variation in the ZP of CT-NLC+, R-NLC+, and L-NLC+ $(\sim+20 \mathrm{mV})$ was observed after incubation with mucin owing to the mucin coating. According to turbidimetric results, the interaction was higher for NLC + with EOs in the following order: L-NLC+ > R-NLC+ > CT-NLC+.

Mucins are highly glycosylated glycoproteins with a large peptide backbone and oligosaccharides as side chains. Their protein backbone is characterized by the presence of repeating sequences rich in serine, threonine, and proline residues. The net negative charge is due to the presence of deprotonated carboxylate groups (sialic acid) and ester sulfates at the terminus of some sugar units [78]. The mucoadhesive study was carried out at a specific $\mathrm{pH}$ value ( $\mathrm{pH}$ 5.8) according to the intranasal administration route. The loss of electrostatic interaction of mucin at low $\mathrm{pH}$ led to a conformational change from a random coil to a rod-like structure by exposing hydrophobic regions, which were folded and sequestered in the inner part at neutral $\mathrm{pH}$. This is a favorable condition for the 
interactions between mucin and other entities $[77,79]$. The electrostatic interaction is the most expectable mucoadhesive mechanism. This may be due to the interactions between the negatively charged sialic groups of mucin and DDAB tertiary amino group present on the nanoparticles surface. Therefore, the reduction of $\mathrm{ZP}$ values observed for all NLC+ after 1 and $24 \mathrm{~h}$ of incubation with mucin could be attributed to the ionic interaction between the negatively charged mucin particles and NLC+. As a result, the interaction led to a decrease in NLC+ motion, which in turn could decrease their wash out by nasal mucociliary motion after administration, limiting the loss due to sneezing, thus allowing the sustained and prolonged release of the EO to directly reach the brain. These findings are very promising, because, although nasal drug delivery offers direct access of the therapeutics to the brain, it faces hindrances, such as the mucociliary clearance, that prevents drug retention at the mucosal surface with consequent loss of drug therapeutic effectiveness [80,81]. Mucoadhesive carriers could overcome this issue by prolonging the residence time of the drug in the nasal area, thereby increasing absorption and resulting in a remarkable therapeutic response [81].

\section{Conclusions}

Taken together, our results show that the use of Lavandula or Rosmarinus allowed the formation of smaller and more homogeneous nanoparticles, with a more ordered structure related to the formation of oily droplets into the lipid matrix compared to the other tested oils. The results of in vitro studies show that EO nanoencapsulation provides a sustained and prolonged release. Furthermore, Lavandula and Rosmarinus NLC were safe on both murine and human cell lines, at all tested concentrations. This preliminary study suggests that optimized positively charged NLC containing Lavandula or Rosmarinus can be proposed as a potential add-on strategy in the treatment of neurodegenerative diseases through intranasal administration, due to the well-known beneficial effects of essential oils and the mucoadhesive properties of the prepared NLC.

Supplementary Materials: The following are available online at https:/ /www.mdpi.com/article/10 .3390 / pharmaceutics13081166/s1, Figure S1: Mean particle size (Zave, nm), polydispersity index (PDI) and Zeta Potentia (ZP) \pm standard deviation (SD) of the prepared Lavandula NLC (L-NLC), Mentha NLC (M-NLC), Rosmarinus NLC (R-NLC), Tegosoft CT NLC (CT-NLC) and Neem NLC (NNLC) analysed after 30 days of storage in Turbiscan, Figure S2: Raman spectra of all the prepared NLC, Figure S3: XRD spectra of all the prepared NLC, Figure S4: Transmission electron microscopy (TEM) images of NLC prepared using Mentha EO (M-NLC), Figure S5: Transmission electron microscopy (TEM) images of NLC prepared using Rosmarinus EO (R-NLC), Table S1: Raman parameters for the $\mathrm{C}-\mathrm{H}$ stretching vibrational bands of NLC systems.

Author Contributions: A.B., C.C. (Cinzia Cimino), D.E.M., B.T., and A.S., investigation, data curation, and writing — original draft; T.M., writing — review and editing, funding; G.P. and R.P., writingreview and editing; C.C. (Claudia Carbone), conceptualization, investigation, methodology, data curation, writing —original draft, writing — review and editing, and supervision. All authors have read and agreed to the published version of the manuscript.

Funding: This research was supported by University of Catania Programma Ricerca di Ateneo Unict 2020-2022-Linea 2 (Project: 3N-ORACLE). Cinzia Cimino was supported by the PhD program in Biotechnology, XXXVI cycle, University of Catania.

Institutional Review Board Statement: Not applicable.

Informed Consent Statement: Not applicable.

Data Availability Statement: The data presented in this study are available on request from the corresponding author.

Conflicts of Interest: The authors declare no conflict of interest. 


\section{References}

1. Bilia, A.R.; Guccione, C.; Isacchi, B.; Righeschi, C.; Firenzuoli, F.; Bergonzi, M.C. Essential oils loaded in canosystems: A developing strategy for a successful therapeutic approach. Evid. Based Complement. Altern. Med. 2014, 651593. [CrossRef]

2. Bilia, A.R.; Santomauro, F.; Sacco, C.; Bergonzi, M.C.; Donato, R. Essential oil of Artemisia annua L.: An extraordinary component with numerous antimicrobial properties. Evid. Based Complement. Altern. Med. 2014, 159819. [CrossRef]

3. Cacciatore, F.A.; Dalmas, M.; Maders, C.; Isaia, H.A.; Brandelli, A.; Malheiros, P.D. Carvacrol encapsulation into nanostructures: Characterization and antimicrobial activity against foodborne pathogens adhered to stainless steel. Food Res. Int. $2020,133$. [CrossRef]

4. Carbone, C.; Martins-Gomes, C.; Caddeo, C.; Silva, A.M.; Musumeci, T.; Pignatello, R.; Puglisi, G.; Souto, E.B. Mediterranean essential oils as precious matrix components and active ingredients of lipid nanoparticles. Int. J. Pharm. 2018, 548, 217-226. [CrossRef] [PubMed]

5. Celia, C.; Trapasso, E.; Locatelli, M.; Navarra, M.; Ventura, C.A.; Wolfram, J.; Carafa, M.; Morittu, V.M.; Britti, D.; Di Marzio, L.; et al. Anticancer activity of liposomal Bergamot essential oil (Beo) on human neuroblastoma cells. Colloids Surf. B Biointerfaces 2013, 112, 548-553. [CrossRef]

6. Donato, R.S.; Santomauro, F.; Bilia, A.R.; Flamini, G.; Sacco, C. Antibacterial activity of Tuscan Artemisia annua essential oil and its major components against some foodborne pathogens. LWT Food Sci. Technol. 2015, 64, 1251-1254. [CrossRef]

7. Donsi, F.; Annunziata, M.; Sessa, M.; Ferrari, G. Nanoencapsulation of essential oils to enhance their antimicrobial activity in foods. LWT Food Sci. Technol. 2011, 44, 1908-1914. [CrossRef]

8. Lai, F.; Wissing, S.A.; Muller, R.H.; Fadda, A.M. Artemisia arborescens L essential oil-loaded solid lipid nanoparticles for potential agricultural application: Preparation and characterization. AAPS PharmSciTech 2006, 7, E2. [CrossRef]

9. Mannucci, C.; Calapai, F.; Cardia, L.; Inferrera, G.; D’Arena, G.; Di Pietro, M.; Navarra, M.; Gangemi, S.; Ventura Spagnolo, E.; Calapai, G. Clinical pharmacology of Citrus aurantium and Citrus sinensis for the treatment of anxiety. Evid. Based Complement. Altern. Med. 2018, 2018, 3624094. [CrossRef]

10. Montenegro, L.; Pasquinucci, L.; Zappala, A.; Chiechio, S.; Turnaturi, R.; Parenti, C. Rosemary essential oil-loaded lipid nanoparticles: In vivo topical activity from gel vehicles. Pharmaceutics 2017, 9, 48. [CrossRef]

11. Saporito, F.; Sandri, G.; Bonferoni, M.C.; Rossi, S.; Boselli, C.; Icaro Cornaglia, A.; Mannucci, B.; Grisoli, P.; Vigani, B.; Ferrari, F. Essential oil-loaded lipid nanoparticles for wound healing. Int. J. Nanomed. 2018, 13, 175-186. [CrossRef]

12. Scuteri, D.; Morrone, L.A.; Rombola, L.; Avato, P.R.; Bilia, A.R.; Corasaniti, M.T.; Sakurada, S.; Sakurada, T.; Bagetta, G. Aromatherapy and aromatic plants for the treatment of behavioural and psychological symptoms of dementia in patients with Alzheimer's disease: Clinical evidence and possible mechanisms. Evid. Based Complement. Altern. Med. 2017, $2017,9416305$. [CrossRef] [PubMed]

13. Sinico, C.; De Logu, A.; Lai, F.; Valenti, D.; Manconi, M.; Loy, G.; Bonsignore, L.; Fadda, A.M. Liposomal incorporation of Artemisia arborescens L. essential oil and in vitro antiviral activity. Eur. J. Pharm. Biopharm. 2005, 59, 161-168. [CrossRef] [PubMed]

14. Manconi, M.; Petretto, G.; D’Hallewin, G.; Escribano, E.; Milia, E.; Pinna, R.; Palmieri, A.; Firoznezhad, M.; Peris, J.E.; Usach, I.; et al. Thymus essential oil extraction, characterization and incorporation in phospholipid vesicles for the antioxidant/antibacterial treatment of oral cavity diseases. Colloids Surf. B Biointerfaces 2018, 171, 115-122. [CrossRef] [PubMed]

15. Carbone, C.; Caddeo, C.; Grimaudo, M.A.; Manno, D.E.; Serra, A.; Musumeci, T. Ferulic acid-NLC with Lavandula essential oil: A possible strategy for wound-Hhealing? Nanomaterials 2020, 10, 898. [CrossRef]

16. Carbone, C.; Teixeira, M.D.C.; Sousa, M.D.C.; Martins-Gomes, C.; Silva, A.M.; Souto, E.M.B.; Musumeci, T. Clotrimazole-loaded Mediterranean essential oils NLC: A synergic treatment of Candida skin infections. Pharmaceutics 2019, 11, 231. [CrossRef] [PubMed]

17. Jimbo, D.; Kimura, Y.; Taniguchi, M.; Inoue, M.; Urakami, K. Effect of aromatherapy on patients with Alzheimer's disease. Psychogeriatrics 2009, 9, 173-179. [CrossRef]

18. Rinaldi, F.; Oliva, A.; Sabatino, M.; Imbriano, A.; Hanieh, P.N.; Garzoli, S.; Mastroianni, C.M.; De Angelis, M.; Miele, M.C.; Arnaut, M.; et al. Antimicrobial essential oil formulation: Chitosan coated nanoemulsions for nose to brain delivery. Pharmaceutics 2020, 12, 678. [CrossRef]

19. Battaglia, L.; Panciani, P.P.; Muntoni, E.; Capucchio, M.T.; Biasibetti, E.; De Bonis, P.; Mioletti, S.; Fontanella, M.; Swaminathan, S. Lipid nanoparticles for intranasal administration: Application to nose-to-brain delivery. Expert Opin. Drug Deliv. 2018, 15, 369-378. [CrossRef]

20. Blasi, P.; Giovagnoli, S.; Schoubben, A.; Puglia, C.; Bonina, F.; Rossi, C.; Ricci, M. Lipid nanoparticles for brain targeting I. Formulation optimization. Int. J. Pharm. 2011, 419, 287-295. [CrossRef]

21. Blasi, P.; Giovagnoli, S.; Schoubben, A.; Ricci, M.; Rossi, C. Solid lipid nanoparticles for targeted brain drug delivery. Adv. Drug Deliv. Rev. 2007, 59, 454-477. [CrossRef] [PubMed]

22. Blasi, P.; Schoubben, A.; Giovagnoli, S.; Rossi, C.; Ricci, M. Lipid nanoparticles for drug delivery to the brain: In vivo veritas. J. Biomed. Nanotechnol. 2009, 5, 344-350. [CrossRef]

23. Blasi, P.; Schoubben, A.; Romano, G.V.; Giovagnoli, S.; Di Michele, A.; Ricci, M. Lipid nanoparticles for brain targeting II. Technological characterization. Colloids Surf. B Biointerfaces 2013, 110, 130-137. [CrossRef]

24. Blasi, P.; Schoubben, A.; Traina, G.; Manfroni, G.; Barberini, L.; Alberti, P.F.; Cirotto, C.; Ricci, M. Lipid nanoparticles for brain targeting III. Long-term stability and in vivo toxicity. Int. J. Pharm. 2013, 454, 316-323. [CrossRef] 
25. Bonaccorso, A.; Pellitteri, R.; Ruozi, B.; Puglia, C.; Santonocito, D.; Pignatello, R.; Musumeci, T. Curcumin loaded polymeric vs. lipid nanoparticles: Antioxidant effect on normal and hypoxic olfactory ensheathing cells. Nanomaterials 2021, 11, 159. [CrossRef] [PubMed]

26. Cometa, S.; Bonifacio, M.A.; Trapani, G.; Di Gioia, S.; Dazzi, L.; De Giglio, E.; Trapani, A. In vitro investigations on dopamine loaded solid lipid nanoparticles. J. Pharm. Biomed. Anal. 2020, 185, 113257. [CrossRef]

27. de Oliveira Junior, E.R.; Truzzi, E.; Ferraro, L.; Fogagnolo, M.; Pavan, B.; Beggiato, S.; Rustichelli, C.; Maretti, E.; Lima, E.M.; Leo, E.; et al. Nasal administration of nanoencapsulated geraniol/ursodeoxycholic acid conjugate: Towards a new approach for the management of Parkinson's disease. J. Control. Release 2020, 321, 540-552. [CrossRef] [PubMed]

28. Rassu, G.; Soddu, E.; Posadino, A.M.; Pintus, G.; Sarmento, B.; Giunchedi, P.; Gavini, E. Nose-to-brain delivery of bace1 sirna loaded in solid lipid nanoparticles for Alzheimer's therapy. Colloids Surf. B Biointerfaces 2017, 152, 296-301. [CrossRef]

29. Gavini, E.; Rassu, G.; Ferraro, L.; Beggiato, S.; Alhalaweh, A.; Velaga, S.; Marchetti, N.; Bandiera, P.; Giunchedi, P.; Dalpiaz, A. influence of polymeric microcarriers on the in vivo intranasal uptake of an anti-migraine drug for brain targeting. Eur. J. Pharm. Biopharm. 2013, 83, 174-183. [CrossRef]

30. Gavini, E.; Rassu, G.; Ferraro, L.; Generosi, A.; Rau, J.V.; Brunetti, A.; Giunchedi, P.; Dalpiaz, A. Influence of chitosan glutamate on the in vivo intranasal absorption of rokitamycin from microspheres. J. Pharm. Sci. 2011, 100, 1488-1502. [CrossRef] [PubMed]

31. Rassu, G.; Porcu, E.P.; Fancello, S.; Obinu, A.; Senes, N.; Galleri, G.; Migheli, R.; Gavini, E.; Giunchedi, P. Intranasal delivery of genistein-loaded nanoparticles as a potential preventive system against neurodegenerative disorders. Pharmaceutics 2018, 11, 8. [CrossRef]

32. Arduino, I.; Iacobazzi, R.M.; Riganti, C.; Lopedota, A.A.; Perrone, M.G.; Lopalco, A.; Cutrignelli, A.; Cantore, M.; Laquintana, V.; Franco, M.; et al. Induced expression of p-gp and bcrp transporters on brain endothelial cells using transferrin functionalized nanostructured lipid carriers: A first step of a potential strategy for the treatment of Alzheimer's disease. Int. J. Pharm. 2020, 591, 120011. [CrossRef]

33. Hritcu, L.; Cioanca, O.; Hancianu, M. Effects of Lavender oil inhalation on improving scopolamine-induced spatial memory impairment in laboratory rats. Phytomedicine 2012, 19, 529-534. [CrossRef]

34. Satou, T.H.; Hanashima, Y.; Mizutani, I.; Koike, K. The effect of inhalation of essential oil from Rosmarinus Officinalis on scopolamine-induced Alzheimer's type dementia model in mice. Flavour Fragr. J. 2017, 33, 1-5. [CrossRef]

35. Filiptsova, O.V.; Gazzavi-Rogozina, L.V.; Timoshyna, I.A.; Naboka, O.I.; Dyomina Ye, V.; Ochkur, A.V. The effect of the essential oils of Lavender and Rosemary on the human short-term memory. Alexandria J. Med. 2018, 54, 41-44. [CrossRef]

36. Ali-Shtayeh, M.S.; Jamous, R.M.; Abu-Zaitoun, S.Y.; Khasati, A.I.; Kalbouneh, S.R. Biological properties and bioactive components of Mentha Spicata L. essential oil: Focus on potential benefits in the treatment of obesity, Alzheimer's disease, dermatophytosis, and drug-resistant infections. Evid. Based Complement. Altern. Med. 2019, 2019, 3834265. [CrossRef] [PubMed]

37. Suresha, A.R.; Rajesh, P.; Anil Raj, K.S.; Torgal, R. A rare case of toxic optic neuropathy secondary to consumption of Neem oil. Indian J. Ophthalmol. 2014, 62, 337-339. [CrossRef]

38. Rahman, M.F.; Siddiqui, M.K.; Jamil, K. Sub-Chronic Effect of Neem based pesticide (Vepacide) on acetylcholinesterase and atpases in rat. J. Environ. Sci. Health B 1999, 34, 873-884. [CrossRef]

39. Lai, S.M.; Lim, K.W.; Cheng, H.K. Margosa oil poisoning as a cause of toxic encephalopathy. Singapore Med. J. 1990, 31, 463-465. [PubMed]

40. Carbone, C.; Campisi, A.; Musumeci, T.; Raciti, G.; Bonfanti, R.; Puglisi, G. Fa-loaded lipid drug delivery systems: Preparation, characterization and biological studies. Eur. J. Pharm. Sci. 2014, 52, 12-20. [CrossRef]

41. Caddeo, C.; Pucci, L.; Gabriele, M.; Carbone, C.; Fernandez-Busquets, X.; Valenti, D.; Pons, R.; Vassallo, A.; Fadda, A.M.; Manconi, M. Stability, biocompatibility and antioxidant activity of peg-modified liposomes containing resveratrol. Int. J. Pharm. 2018, 538, 40-47. [CrossRef]

42. Rezvani, M.; Manca, M.L.; Caddeo, C.; Escribano-Ferrer, E.; Carbone, C.; Peris, J.E.; Usach, I.; Diez-Sales, O.; Fadda, A.M.; Manconi, M. Co-loading of ascorbic acid and tocopherol in eudragit-nutriosomes to counteract intestinal oxidative stress. Pharmaceutics 2019, 11, 13. [CrossRef] [PubMed]

43. Carbone, C.; Musumeci, T.; Lauro, M.R.; Puglisi, G. Eco-friendly aqueous core surface-modified nanocapsules. Colloids Surf. B Biointerfaces 2015, 125, 190-196. [CrossRef] [PubMed]

44. Santonocito, D.; Sarpietro, M.G.; Carbone, C.; Panico, A.; Campisi, A.; Siciliano, E.A.; Sposito, G.; Castelli, F.; Puglia, C. Curcumin containing pegylated solid lipid nanoparticles for systemic administration: A preliminary study. Molecules 2020, $25,2991$. [CrossRef]

45. Puglia, C.; Santonocito, D.; Ostacolo, C.; Maria Sommella, E.; Campiglia, P.; Carbone, C.; Drago, F.; Pignatello, R.; Bucolo, C. Ocular formulation based on palmitoylethanolamide-loaded nanostructured lipid carriers: Technological and pharmacological profile. Nanomaterials 2020, 10, 287. [CrossRef]

46. Carbone, C.; Manno, D.; Serra, A.; Musumeci, T.; Pepe, V.; Tisserand, C.; Puglisi, G. Innovative hybrid vs polymeric nanocapsules: The influence of the cationic lipid coating on the "4s". Colloids Surf. B Biointerfaces 2016, 141, 450-457. [CrossRef]

47. Castile, J.; Cheng, Y.H.; Simmons, B.; Perelman, M.; Smith, A.; Watts, P. Development of in Vitro Models to Demonstrate the Ability of Pecsys (R), an in Situ Nasal Gelling Technology, to Reduce Nasal Run-Off and Drip. Drug Dev. Ind. Pharm. 2013, 39, 816-824. [CrossRef] 
48. Tomasello, B.; Di Mauro, M.D.; Malfa, G.A.; Acquaviva, R.; Sinatra, F.; Spampinato, G.; Laudani, S.; Villaggio, G.; BielakZmijewska, A.; Grabowska, W.; et al. Rapha $\operatorname{Myr}((\mathrm{R}))$, a blend of sulforaphane and myrosinase, exerts antitumor and anoikissensitizing effects on human astrocytoma cells modulating sirtuins and DNA methylation. Int. J. Mol. Sci. 2020, $21,5328$. [CrossRef]

49. Carbone, C.; Campisi, A.; Manno, D.; Serra, A.; Spatuzza, M.; Musumeci, T.; Bonfanti, R.; Puglisi, G. The critical role of didodecyldimethylammonium bromide on physico-chemical, technological and biological properties of NLC. Colloids Surf. B Biointerfaces 2014, 121, 1-10. [CrossRef]

50. Danaei, M.; Dehghankhold, M.; Ataei, S.; Hasanzadeh Davarani, F.; Javanmard, R.; Dokhani, A.; Khorasani, S.; Mozafari, M.R. Impact of particle size and polydispersity index on the clinical applications of lipidic nanocarrier systems. Pharmaceutics 2018, 10, 57. [CrossRef] [PubMed]

51. Lang, F.; Busch, G.L.; Volkl, H. The diversity of volume regulatory mechanisms. Cell. Physiol. Biochem. 1998, 8, 1-45. [CrossRef] [PubMed]

52. Patravale, V.B.; Date, A.A.; Kulkarni, R.M. Nanosuspensions: A promising drug delivery strategy. J. Pharm. Pharmacol. 2004, 56, 827-840. [CrossRef] [PubMed]

53. Musumeci, T.; Bonaccorso, A.; Carbone, C.; Russo, G.; Pappalardo, F.; Puglisi, G. Design and optimization of pegylated nanoparticles intended for berberine chloride delivery. J. Drug Deliv. Sci. Technol. 2019, 52, 521-530. [CrossRef]

54. Esmonde-White, K.A.; Cuellar, M.; Uerpmann, C.; Lenain, B.; Lewis, I.R. Raman spectroscopy as a process analytical technology for pharmaceutical manufacturing and bioprocessing. Anal. Bioanal. Chem. 2017, 409, 637-649. [CrossRef]

55. Chauhan, I.; Yasir, M.; Verma, M.; Singh, A.P. Nanostructured lipid carriers: A groundbreaking approach for transdermal drug delivery. Ad. Pharm. Bull. 2020, 10, 150-165. [CrossRef]

56. Spiker, R.C.; Levin, I.W. Effect of bilayer curvature on vibrational Raman spectroscopic behavior of phospholipid-water assemblies. Biochim. Biophys. Acta 1976, 455, 560-575. [CrossRef]

57. De Lange, M.J.L.; Bonn, M.; Muller, M. Direct Measurements of Phase Coexistence in Dppc/Cholesterol Vesicles Using Raman Spectroscopy. Chem. Phys. Lipids 2007, 146, 76-84. [CrossRef] [PubMed]

58. Schultz, Z.D.; Levin, I.W. Vibrational spectroscopy of biomembranes. Annu. Rev. Anal. Chem. 2011, 4, 343-366. [CrossRef] [PubMed]

59. George, W.H.; Wurpel, J.M.S.; Muller, M. Direct measurement of chain order in single phospholipid mono- and bilayers with multiplex cars. J. Phys. Chem. B 2004, 108, 3400-3403.

60. Sato, K.; Ueno, S.; Yano, J. Molecular interactions and kinetic properties of fats. Prog. Lipid Res. 1999, 38, 91-116. [CrossRef]

61. Teeranachaideekul, V.; Morakul, B.; Boonme, P.; Pornputtapitak, W.; Junyaprasert, V. Effect of lipid and oil compositions on physicochemical properties and photoprotection of octyl methoxycinnamate-loaded nanostructured lipid carriers (NLC). J. Oleo Sci. 2020, 69, 1627-1639. [CrossRef] [PubMed]

62. Tetyczka, C.; Hodzic, A.; Kriechbaum, M.; Juraic, K.; Spirk, C.; Hartl, S.; Pritz, E.; Leitinger, G.; Roblegg, E. Comprehensive characterization of nanostructured lipid carriers using laboratory and synchrotron X-ray scattering and diffraction. Eur. J. Pharm. Biopharm. 2019, 139, 153-160. [CrossRef]

63. Mostafa, D.A.; Bayoumi, F.S.; Taher, H.M.; Abdelmonem, B.H.; Eissa, T.F. Antimicrobial Potential of Mentha Spp. Essential Oils as Raw and Loaded Solid Lipid Nanoparticles against Dental Caries. Res. J. Pharm. Technol. 2020, 13, 4415-4422. [CrossRef]

64. Pasquoto-Stigliani, T.; Campos, E.V.R.; Oliveira, J.L.; Silva, C.M.G.; Bilesky-Jose, N.; Guilger, M.; Troost, J.; Oliveira, H.C.; Stolf-Moreira, R.; Fraceto, L.F.; et al. Nanocapsules containing Neem (Azadirachta indica) oil: Development, characterization, and toxicity evaluation. Sci. Rep. 2017, 7. [CrossRef]

65. Reeta, M.R.; Newton, A.M.J. Fabrication and characterisation of Lavender oil and plant phospholipid based sumatriptan succinate hybrid nano lipid carriers. Pharm. Biomed. Res. 2020, 6, 91-104. [CrossRef]

66. Vieira, R.; Severino, P.; Nalone, L.A.; Souto, S.B.; Silva, A.M.; Lucarini, M.; Durazzo, A.; Santini, A.; Souto, E.B. Sucupira Oil-Loaded Nanostructured Lipid Carriers (Nlc): Lipid Screening, Factorial Design, Release Profile, and Cytotoxicity. Molecules 2020, 25, 685. [CrossRef] [PubMed]

67. Yun, Y.R.; Won, J.E.; Jeon, E.; Lee, S.; Kang, W.; Jo, H.; Jang, J.H.; Shin, U.S.; Kim, H.W. Fibroblast growth factors: Biology, function, and application for tissue regeneration. J. Tissue Eng. 2010, 2010, 218142. [CrossRef]

68. Srivastava, P.; Yadav, N.; Lella, R.; Schneider, A.; Jones, A.; Marlowe, T.; Lovett, G.; O’Loughlin, K.; Minderman, H.; Gogada, R.; et al. Neem Oil Limonoids Induces P53-Independent Apoptosis and Autophagy. Carcinogenesis 2012, 33, 2199-2207. [CrossRef] [PubMed]

69. Brahmi, F.; Hadj-Ahmed, S.; Zarrouk, A.; Bezine, M.; Nury, T.; Madani, K.; Chibane, M.; Vejux, A.; Andreoletti, P.; BoulekbacheMakhlouf, L.; et al. Evidence of biological activity of Mentha species extracts on apoptotic and autophagic targets on murine raw264.7 and human U937 monocytic cells. Pharm. Biol. 2017, 55, 286-293. [CrossRef]

70. Torres-Martinez, Y.; Arredondo-Espinoza, E.; Puente, C.; Gonzalez-Santiago, O.; Pineda-Aguilar, N.; Balderas-Renteria, I.; Lopez, I.; Ramirez-Cabrera, M.A. Synthesis of silver nanoparticles using a Mentha Spicata extract and evaluation of its anticancer and cytotoxic activity. PeerJ 2019, 7, e8142. [CrossRef]

71. Silva, A.M.; Martins-Gomes, C.; Coutinho, T.E.; Fangueiro, J.E.; Sanchez-Lopez, E.; Pashirova, T.N.; Andreani, T.; Souto, E.B. Soft cationic nanoparticles for drug delivery: Production and cytotoxicity of solid lipid nanoparticles (SLNs). Appl. Sci. 2019, 9, 4438. [CrossRef] 
72. Makled, S.; Nafee, N.; Boraie, N. Nebulized Solid lipid nanoparticles for the potential treatment of pulmonary hypertension via targeted delivery of phosphodiesterase-5-inhibitor. Int. J. Pharm. 2017, 517, 312-321. [CrossRef] [PubMed]

73. Amore, E.; Ferraro, M.; Manca, M.L.; Gjomarkaj, M.; Giammona, G.; Pace, E.; Bondi, M.L. Mucoadhesive solid lipid microparticles for controlled release of a corticosteroid in the chronic obstructive pulmonary disease treatment. Nanomedicine 2017, 12, 2287-2302. [CrossRef] [PubMed]

74. Rencber, S.; Karavana, S.Y.; Yilmaz, F.F.; Erac, B.; Nenni, M.; Ozbal, S.; Pekcetin, C.; Gurer-Orhan, H.; Hosgor-Limoncu, M.; Guneri, P.; et al. Development, characterization, and in vivo assessment of mucoadhesive nanoparticles containing fluconazole for the local treatment of oral candidiasis. Int. J. Nanomed. 2016, 11, 2641-2653. [CrossRef]

75. Sallam, M.A.; Helal, H.M.; Mortada, S.M. Rationally designed nanocarriers for intranasaltherapy of allergic rhinitis: Influence of carrier type on in vivo nasal deposition. Int. J. Nanomed. 2016, 11, 2345-2357. [CrossRef] [PubMed]

76. D'Angelo, I.; Casciaro, B.; Miro, A.; Quaglia, F.; Mangoni, M.L.; Ungaro, F. Overcoming barriers in Pseudomonas Aeruginosa lung infections: Engineered nanoparticles for local delivery of a cationic antimicrobial peptide. Colloids Surf. B Biointerfaces 2015, 135, 717-725. [CrossRef]

77. Bonaccorso, A.; Musumeci, T.; Carbone, C.; Vicari, L.; Lauro, M.R.; Puglisi, G. Revisiting the role of sucrose in PLGA-PEG nanocarrier for potential intranasal delivery. Pharm. Dev. Technol. 2018, 23, 265-274. [CrossRef]

78. Szilagyi, B.A.; Mammadova, A.; Gyarmati, B.; Szilagyi, A. Mucoadhesive interactions between synthetic polyaspartamides and porcine gastric mucin on the colloid size scale. Colloids Surf. B Biointerfaces 2020, 194, 111219. [CrossRef]

79. das Neves, J.; Sverdlov Arzi, R.; Sosnik, A. Molecular and cellular cues governing nanomaterial-mucosae interactions: From nanomedicine to nanotoxicology. Chem. Soc. Rev. 2020, 49, 5058-5100. [CrossRef]

80. Musumeci, T.; Bonaccorso, A.; Puglisi, G. Epilepsy disease and nose-to-brain delivery of polymeric nanoparticles: An overview. Pharmaceutics 2019, 11, 118. [CrossRef]

81. Rehman, S.; Nabi, B.; Zafar, A.; Baboota, S.; Ali, J. Intranasal delivery of mucoadhesive nanocarriers: A viable option for Parkinson's disease treatment? Expert Opin. Drug Deliv. 2019, 16, 1355-1366. [CrossRef] [PubMed] 